\title{
Magnetic Resonance Imaging of Myelin
}

\author{
Cornelia Laule, ${ }^{*}$ Irene M. Vavasour,* Shannon H. Kolind, ${ }^{\dagger}$ David K. B. Li,* \\ Tony L. Traboulsee, ${ }^{*}$ G. R. Wayne Moore, ${ }^{\S}$ and Alex L. MacKay*† \\ *Department of Radiology, ${ }^{\dagger}$ Department of Physics and Astronomy, ${ }^{\ddagger}$ Department of Medicine, ${ }^{\S}$ Department of Pathology \& \\ Laboratory and Medicine (Neuropathology), University of British Columbia, Vancouver, BC, V6T 2 B5 Canada
}

\begin{abstract}
Summary: The ability to measure myelin in vivo has great consequences for furthering our knowledge of normal development, as well as for understanding a wide range of neurological disorders. The following review summarizes the current state of myelin imaging using MR. We consider five MR techniques that have been used to study myelin: 1) conventional MR, 2) MR spectroscopy, 3) diffusion, 4) magnetization transfer, and 5) $\mathrm{T}_{2}$ relaxation. Fundamental studies involving pe-
\end{abstract}

ripheral nerve and MR/histology comparisons have aided in the interpretation and validation of MR data. We highlight a number of important findings related to myelin development, damage, and repair, and we conclude with a critical summary of the current techniques available and their potential to image myelin in vivo. Key Words: Myelin, MR, histologic validation, $\mathrm{T}_{2}$, diffusion, magnetization transfer, MR spectroscopy.

\section{INTRODUCTION}

The ability to measure myelin in vivo has far reaching consequences both for our understanding of normal development of the nervous system, as well as for the characterization of a wide variety of neurological disorders. Until fairly recently, our knowledge of myelin development and pathology was limited to that acquired from postmortem studies. Although pathological studies still remain the gold standard, advances in imaging now allow us to image changes in the brain in vivo using MR. Unfortunately, despite much effort and progress in MR in recent years, there is still no MR technique capable of assessing the myelin bilayer explicitly. However, a number of MR techniques are available that attempt to study myelin by indirect methods, through which we may further our understanding of myelin development, damage, and repair.

The following review provides a comprehensive summary of the current state of imaging myelin using MR. We begin with a background of the structure and function of myelin, and then briefly review the current MR techniques used to assess myelin (i.e., conventional MR, MR spectroscopy, diffusion, magnetization transfer, and $\mathrm{T}_{2}$ relaxation). We present an expanded section on $\mathrm{T}_{2}$

Address correspondence and reprint requests to: Cornelia Laule, Department of Radiology, University of British Columbia Hospital, Room M10, Purdy Pavilion/ECU, 2221 Wesbrook Mall, Vancouver, BC V6T 2B5 Canada. E-mail: claule@ physics.ubc.ca. relaxation, because this approach is not as well known as the others and is not covered elsewhere in this special issue. We highlight fundamental studies in peripheral nerve and summarize a number of important histological validation studies. We explore what we have learned about myelin development, myelin damage, and myelin repair from MR and, finally, we conclude with a critical summary of the current techniques available and their potential to image myelin in vivo.

\section{MYELIN}

Myelin is a lipid-protein lamellar membranous structure enveloping axons in both the central and peripheral nervous system of vertebrates. ${ }^{1,2}$ In the CNS, myelin is primarily found in white matter (WM), making up approximately $50 \%$ of the dry weight and giving WM its distinctive color. Myelin is also present in gray matter (GM), although in much smaller quantities.

\section{Myelin structure}

The CNS myelin is produced by oligodendrocytes and is comprised of tightly compacted oligodendrocyte cell membranes, which are wrapped around the axon in a concentric lamellar fashion (FIG.1). Each oligodendrocyte has the ability to produce roughly the same amount of myelin ${ }^{3}$ and can produce $5000 \mathrm{~mm}^{2}$ to $50,000 \mathrm{~mm}^{2}$ of myelin surface area per cell per day, during the period of active myelin assembly. ${ }^{4}$ The axon is not continuously wrapped by my- 


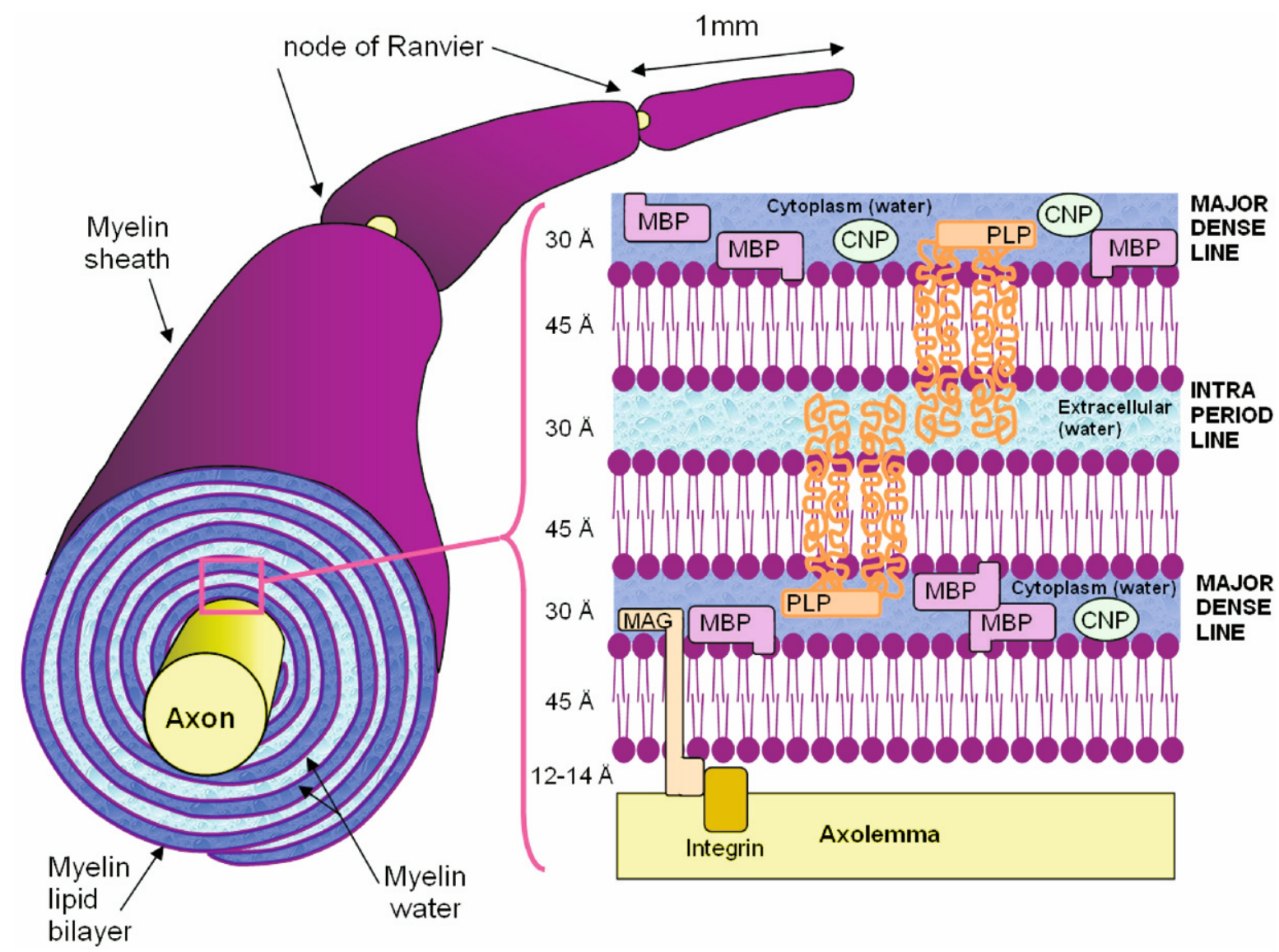

FIG. 1. The CNS myelin sheath surrounding an axon with inset depicting close up of bilayer, including myelin basic protein (MBP), proteolipid protein (PLP), cyclic nucleotide phosphodiesterase (CNP), and myelin-associated glycoprotein (MAG).

elin, but it is focally unmyelinated at loci, termed nodes of Ranvier; the myelinated region between adjacent nodes of Ranvier is referred to as an internode. Each oligodendrocyte can form multiple myelin internodes with multiple axons, and the number of internodes is regulated by axons. When myelination is initiated, all axons are the same size; however, oligodendrocytes appear to have the ability to predict the future diameter of axons and create myelin internodes that are thinner and shorter on those axons that will remain smaller, while myelinating longer and thicker internodes on those axons that will attain a large diameter. ${ }^{3}$ Each myelin internode can be divided into two ultrastructurally and functionally distinct domains: 1) paranodal loops and 2) compact myelin. Paranodal loops facilitate ion exchange at the node of Ranvier by providing a high concentration of sodium channels and compact myelin inhibits ion exchange during nerve conduction. ${ }^{3}$

The myelin bilayer is made up of approximately $80 \%$ lipid and 20\% protein and it is composed of repeating units of the major dense line formed by fusion of the cytoplasmic aspects of the oligodendrocyte process, alternating with the extracellular space between adjacent processes, the intraperiod line. The intraperiod line is thus an extension of the extracellular space and as such should have a relatively high-water content (WC). The intracellular and extracellular space in between the bilayers is filled with water, which makes up approximately $40 \%$ of the weight of myelin ${ }^{1}$ (FIG. 1). Myelin has a periodicity of about 150 angstrom to 160 angstrom. $^{5}$

A variety of proteins contribute to myelin's ultrastructure including ${ }^{3}$ :

1. Myelin Basic Protein (MBP) is a basic protein making up approximately $30 \%$ of the myelin proteins and is localized at the cytoplasmic surface of compact myelin.

2. Proteolipid Protein (PLP) is a hydrophobic protein with four membrane-spanning domains, making up about $50 \%$ of the myelin proteins. The PLP maintains the 30 angstrom extracellular spacing of compact myelin by electrostatic interactions with myelin lipids.

3. Cyclic Nucleotide Phosphodiesterase (CNP) makes up about $4 \%$ of the myelin proteins and is concentrated on the cytoplasmic side of the myelin lamellae. 
4. Myelin-Associated Glycoprotein (MAG) constitutes approximately $1 \%$ of the myelin proteins and may have a role in helping oligodendrocyte processes distinguish between myelinated and unmyelinated axons in the CNS.

5. Myelin Oligodendrocyte Glycoprotein (MOG) is confined to oligodendrocyte bodies and the outermost surface of the myelin sheath. The precise function of MOG is unknown, but it is believed to be important in defining the structural integrity of the myelin sheath.

A variety of lipids also contribute to myelin's ultrastructure including ${ }^{4}$ :

1. Cholesterol accounts for about $30 \%$ of the total lipids and is a critical element in the assembly and integrity of myelin.

2. Phospholipids constitute approximately $40 \%$ of the total lipids in myelin and play a role in biomembrane structure.

3. Glycosphingolipids make up approximately $30 \%$ of the total lipids in myelin and are sometimes also called glycolipids, include cerebrosides, sulfatides, globosides, and gangliosides.

Figure 1 (inset) shows a close-up diagram of the myelin bilayer.

The composition of myelin in the brain is largely, although not completely, conserved among mammalian species (e.g., myelin from rat brain has been shown to have less sphingomyelin than human and bovine myelin). Regional variations also exist within a single species with spinal cord myelin having a higher lipid to protein ratio than myelin from brain tissue from the same species. ${ }^{4}$

\section{Myelin function}

Myelin acts as an electrical insulator for neurons and increases the speed of action potential transmission by 10 to 100 times compared to that along an unmyelinated axon. Myelin is of critical importance because speed of conduction is fundamental in allowing complex motor, sensory, and behavior of neuronal functions to occur. The action potential is mediated by voltage-gated sodium channels located at the nodes of Ranvier, and it jumps from one node of Ranvier to another, with the internodal myelin acting as an insulator of high electrical resistance and low conductance. The resulting saltatory conduction of the action potential is much faster than the continuous conduction by sodium channels evenly distributed along the unmyelinated axon.

Along with its conduction function, myelin has also been implicated in regulating axonal transport, ${ }^{6}$ maintaining axonal integrity, ${ }^{7-9}$ altering $\mathrm{pH}^{10}$, and regulating fluid volume and ion composition. ${ }^{11}$ This highlights the intimate association between myelin and the underlying axon. There is increasing evidence that damage to WM can occur either to myelin or to the axon with subsequent damage to the other. ${ }^{12}$ Consequently, one might anticipate a high correlation between myelin and axonal content; this has indeed been observed in several pathological studies. ${ }^{13,14}$ Therefore, using MR to measure axonal damage and myelin damage separately is often difficult.

\section{REVIEW OF MR TECHNIQUES USED TO ASSESS MYELIN}

Unfortunately, with current technology, it is very difficult, if not impossible to directly image nonaqueous protons in myelin; this is because: 1) their signal decays to zero in a few tens of microseconds, and 2) the MR signal from lipids and proteins in myelin is indistinguishable from that arising from protons on other nonaqueous constituents of CNS tissue. ${ }^{15}$ Two approaches for directly imaging myelin in vivo have been investigated: with ultrashort echo time (TE) imaging ${ }^{16}$ and ${ }^{31} \mathrm{P}$ spectroscopy. ${ }^{17} \mathrm{~A}$ difficulty with ultrashort TE imaging of myelin is removal of the contaminating signal from water, and with ${ }^{31} \mathrm{P}$ spectroscopy there are challenges in quantitative characterization of the signal from phosphatidylcholine head groups. Much more research is required before these approaches will be ready for clinical use. Therefore, practically speaking, MR of myelin is acquired by indirect means. At least five different approaches for indirect myelin imaging have been explored in the literature: 1) conventional $\mathrm{T}_{1}$-weighted and $\mathrm{T}_{2^{-}}$ weighted imaging, 2) spectroscopy, 3) diffusion tensor imaging, 4) magnetization transfer imaging, and 5) separation of $\mathrm{T}_{2}$ relaxation components.

Due to their excellent soft tissue contrast, $\mathrm{T}_{1}$-weighted and $\mathrm{T}_{2}$-weighted images play a large role in clinical MR. Unfortunately, this pathological sensitivity is accompanied by a relatively low specificity because many brain pathologies give rise to similar bright lesions, and for adults there is not a fixed relationship between relaxation time-weighting and myelination. However, the situation is different for newborns and young children in which conventional $\mathrm{T}_{1^{-}}$ weighted and $\mathrm{T}_{2}$-weighted imaging has been used extensively in studies of myelin development. ${ }^{18}$ There is consensus in the literature today that $\mathrm{T}_{1}$ relaxation is primarily determined by WC. ${ }^{19,20}$ It is important to note that this technique implicitly assumes that the only nonaqueous tissue added in early brain development is myelin. Conventional $\mathrm{T}_{1}$-weighting and $\mathrm{T}_{2}$-weighting should be considered a qualitative measure of myelination and has limited application for subjects older than 2 years of age.

The MR spectroscopy potentially provides indirect information about myelin through the existence of peaks from neutral lipids associated with myelin loss and, in some cases, increases in the choline peak presumably associated with the breakdown of phosphatidylcholine 

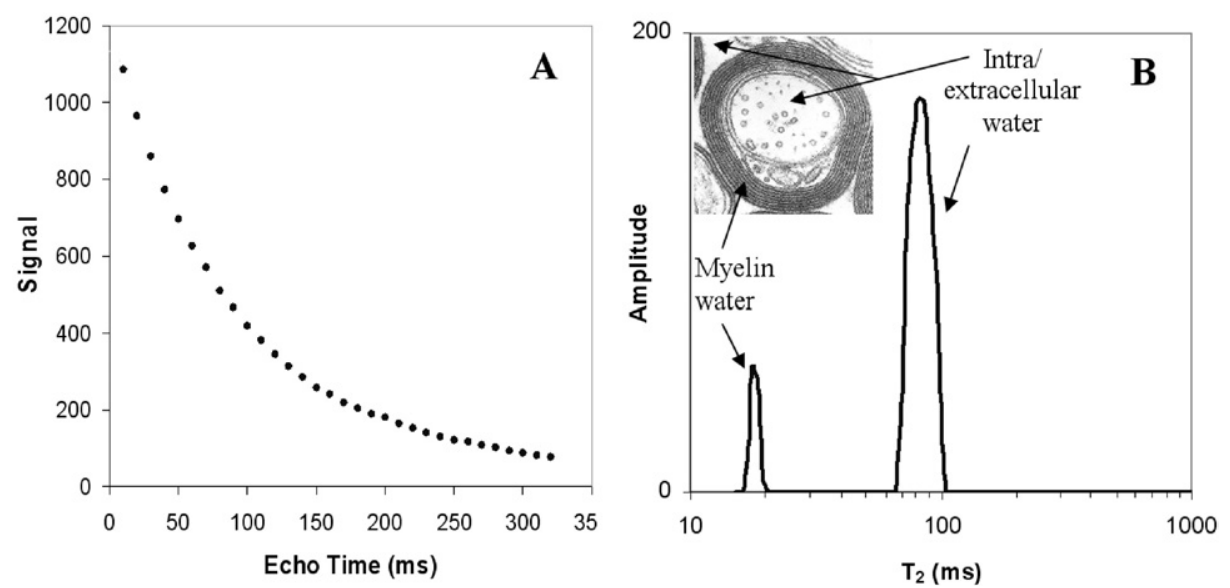

FIG. 2. (A) $T_{2}$ decay curve and (B) $T_{2}$ distribution from human white matter. Inset in (B) shows a cross-section through an axon with the locations of intra/extracellular water and myelin water.

head groups from myelin lipids. Proton magnetic resonance spectroscopy (MRS) is an excellent technique for detecting active demyelination; however, it is not capable of assessing intact myelin.

Diffusion tensor imaging (DTI) measures the kinetics of water molecules. It can be formulated in terms of mean diffusivity $(\langle D\rangle)$ and fractional anisotropy (FA), or more specifically by the axial and radial elements of the water diffusion tensor, $\lambda_{\|}$and $\lambda_{\perp}$, respectively. It has long been known that myelin is not required for the existence of anisotropy in water diffusion in nerves. ${ }^{21}$ However, it has recently been demonstrated ${ }^{22,23}$ in animal models that loss of myelin results in an increase in $\lambda_{\perp}$. Hence, DTI can provide information on changes in myelination; however, it is not a reliable indicator of absolute myelination because the diffusion tensor components depend on the degree of fiber tract orientational order within the imaging voxel.

Magnetization transfer imaging involves detecting the exchange of magnetization between nonaqueous tissue and water. ${ }^{24}$ It is usually measured as a magnetization transfer ratio (MTR), but it has also been modeled to extract tissue parameters (e.g., the fraction of protons on nonaqueous tissue $[\mathrm{F}])^{25-27}$ The large amount of literature on magnetization transfer imaging makes it clear that MTR is a very sensitive measure of tissue damage. However, MTR has been shown to be influenced by other processes such as inflammation, ${ }^{28}$ and it is unlikely to be validated as a specific measure of myelination.

Whereas $\mathrm{T}_{2}$-weighted images are acquired at a single TE time, $T_{2}$ relaxation studies collect the MR signal at a large number of TE times to produce a $\mathrm{T}_{2}$ decay curve. Multi-echo $\mathrm{T}_{2}$ relaxation studies in CNS tissue have revealed the existence of at least two distinguishable water environments, ${ }^{29}$ a short $\mathrm{T}_{2}$ component from water trapped in the myelin sheath, and a longer $T_{2}$ component arising from intracellular and extracellular water. The signal from the "myelin water" can be separated, leading to an indirect measure of myelin, the myelin water frac- tion (MWF). Figure 2 shows a typical $\mathrm{T}_{2}$ decay and corresponding $\mathrm{T}_{2}$ distribution from human WM.

\section{USE OF $T_{2}$ RELAXATION TO MEASURE MYELINATION IN VIVO}

As diffusion, MTR and MRS are reviewed in depth elsewhere in this issue, we present an expanded section on $\mathrm{T}_{2}$ relaxation. The MR signal from the brain is almost entirely from water. Using $T_{2}$ relaxation, the water signal in the brain can be separated into three components: 1) a long $\mathrm{T}_{2}$ component ( $\sim 2 \mathrm{~s}$ ) due to cerebrospinal fluid, 2 ) an intermediate component $(\sim 100 \mathrm{~ms})$ arising from intracellular and extracellular water, and 3) a short $\mathrm{T}_{2}$ component ( $\sim 20 \mathrm{~ms}$ ) believed to be due to water trapped between the myelin bilayers (myelin water) (see FIG. 2). The MWF is calculated by dividing the signal area of the $\mathrm{T}_{2}$ distribution attributed to myelin water $\left(10 \mathrm{~ms}<\mathrm{T}_{2}<\right.$ $50 \mathrm{~ms}$ ) by the total area of the $\mathrm{T}_{2}$ distribution. A myelin water map can be created by displaying the MWF for each pixel in the image. Total WC estimates can be obtained by normalizing the total area of the $\mathrm{T}_{2}$ distribution to an external water standard. ${ }^{30}$

\section{$T_{2}$ data acquisition}

The first step in a $T_{2}$ study is the acquisition of highfidelity $T_{2}$ decay curves. The most common approach is to collect multiple echoes in a single MR sequence. Many investigators have used the Poon-Henkelman multiple echo sequence $^{31}$ that uses rectangular composite $180^{\circ}$ pulses flanked by crushers of decreasing amplitude and alternating sign. This sequence excites the entire signal from the selected slice and results in negligible contributions from a signal originating outside the selected slice. Although this sequence is proven to yield robust $\mathrm{T}_{2}$ decay curves, it suffers from the disadvantage of being a single-slice technique. Modification of the sequence with slice selective refocusing pulses for multiple-slice acquisition is problematic due to 
magnetization transfer effects from off-resonance excitations. This off-resonance effect is complicated by the evidence that exchange between myelin water and nonaqueous myelin occurs at a more rapid rate than exchange between other nonaqueous tissue and the intracellular and extracellular water pool. ${ }^{32-34}$ However, a more practical approach to collecting $\mathrm{T}_{2}$ decay curves was introduced by $\mathrm{Oh}$ et al. ${ }^{35}$ who used a novel spiral acquisition technique ${ }^{36}$ that collected images at $12 \mathrm{TE}$ times for 16 slices in 10 minutes. Mädler et al. ${ }^{37}$ developed a three-dimensional multi-echo pulse sequence that was capable of collecting 32 echoes for multiple slices in less than 20 minutes. Research is underway on variations of the three-dimensional multi-echo sequence, which could reduce scan times for multiple slice $T_{2}$ decay curves to under 10 minutes.

For quantitative analysis, $\mathrm{T}_{2}$ decay curves must have high signal-to-noise ratios with the minimum acceptable noise standard deviation being approximately $1 \%$ of the signal strength at the shortest echo time. ${ }^{38,39}$ The echo spacing should ideally be as short as feasible and the echo train length should be such that the last echoes report only noise. For in vivo human brain studies, the echo spacing should be $10 \mathrm{~ms}$ or less, and the echo train length should exceed $1 \mathrm{~s}$ to measure the shortest $T_{2}$ components and be sensitive to $\mathrm{T}_{2}$ times on the $400 \mathrm{~ms}$ timescale, respectively. Unfortunately, the number of echoes acquired is often limited by considerations of power deposition and MR scanner pulse programmer restrictions.

\section{$T_{2}$ decay curve analysis}

A second challenge in extracting the myelin water signal is the analysis of the $T_{2}$ decay curves in terms of a sum of exponential components. The approach applied most frequently in the literature is non-negative least squares, ${ }^{40,41}$ which uses a $\chi^{2}$ minimization algorithm to fit the decay curve with a $\mathrm{T}_{2}$ distribution (i.e., a plot of amplitude vs $\mathrm{T}_{2}$ time [FIG. 2B]). Non-negative least squares produces a $\mathrm{T}_{2}$ distribution consisting of a few discrete spikes; however, most investigators prefer a smooth distribution. A continuous distribution can be achieved by minimizing $\chi^{2}$ as well as a regularizer. A common regularizer is the sum of the squares of the solution amplitudes-the so-called "small model." ${ }^{40}$ Another approach fits the decay curves to a limited number of Gaussian-shaped $\mathrm{T}_{2}$ peaks. $^{42}$

A very different approach to extracting the myelin water signal is to derive a filter that produces either a myelin water image or a total water image when applied to a series of images acquired at different TE times. Using this novel approach, Jones et al. ${ }^{43}$ and Vidarsson et al. ${ }^{44}$ created myelin water images from a linear combination of as few as three echoes. This linear combination approach could lead to techniques for very fast acquisition of myelin water images.

\section{$T_{2}$ interpretation}

A third challenge to myelin imaging using $\mathrm{T}_{2}$ relaxation is developing the model for interpretation of the $T_{2}$ decay curve as a superposition of signals from different water environments in nervous system tissue. The convention is to interpret the signal with $\mathrm{T}_{2}$ times less than $50 \mathrm{~ms}$ as arising from water in the myelin sheath and the signal with $\mathrm{T}_{2}$ times greater than about $50 \mathrm{~ms}$ as intracellular and extracellular water. In peripheral nerves, the three $T_{2}$ peaks normally observed are attributed to myelin water, axonal water, and extracellular water (FIG. 3). Use of these models presumes that exchange between the various reservoirs is slow on the $T_{2}$ time scale. The presence of exchange would result in a deceased MWF. Evidence thus far ${ }^{32-34}$ suggests that exchange between myelin water and the rest of the water is relatively slow but not completely negligible in CNS tissue and very slow in peripheral nerve system (PNS) tissue. ${ }^{45} \mathrm{~A}$ further issue with this approach is the assumption of a fixed relationship between myelin water and nonaqueous myelin-approximately $40 \%$ by weight in healthy mature WM. ${ }^{1}$ More work is required to explore this relationship in the newborn brain and in pathological WM.

In recent years, a number of groups have embarked on research in the area of $\mathrm{T}_{2}$ relaxation in CNS tissue. Work on myelin water imaging has been published by at least nine groups. ${ }^{29,35,44,46-51}$ Although myelin water imaging is not yet a widely used technique, we are confident that the added participation of these excellent research groups will accelerate technical developments.

\section{PERIPHERAL NERVE}

Although the focus of this review is on CNS myelin, much of the pioneering work using MR to study myelin has been done in the PNS. Both CNS and PNS myelin are functionally similar, but they have slightly different lipid and protein compositions and minor structural differences. ${ }^{3}$ Each internodal segment of PNS myelin is connected to a single Schwann cell, whereas a single oligodendrocyte is connected to several tens of internodal segments of CNS myelin. The internodal distances are longer and the lamellar periodicity is slightly larger in PNS than CNS myelin. Based on the previous statements, one would expect MR results from PNS myelin to be generally translatable to CNS myelin. However, the aforementioned increased lamellar periodicity may lead to a higher WC in PNS myelin.

Almost 40 years ago, Swift and Fritz ${ }^{52}$ demonstrated in bullfrog sciatic nerve that $\mathrm{T}_{2}$ relaxation was not monoexponential. Several decades later, Vasilescu et al. ${ }^{53}$ examined the frog sciatic nerve using a multi-echo technique and found a multiexponential decay giving rise to three distinct $\mathrm{T}_{2}$ components. The authors suggested that the physical compartments associated with these three 


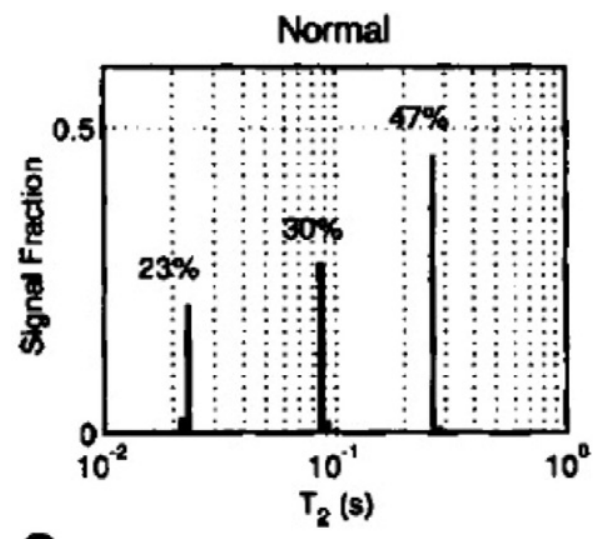

a
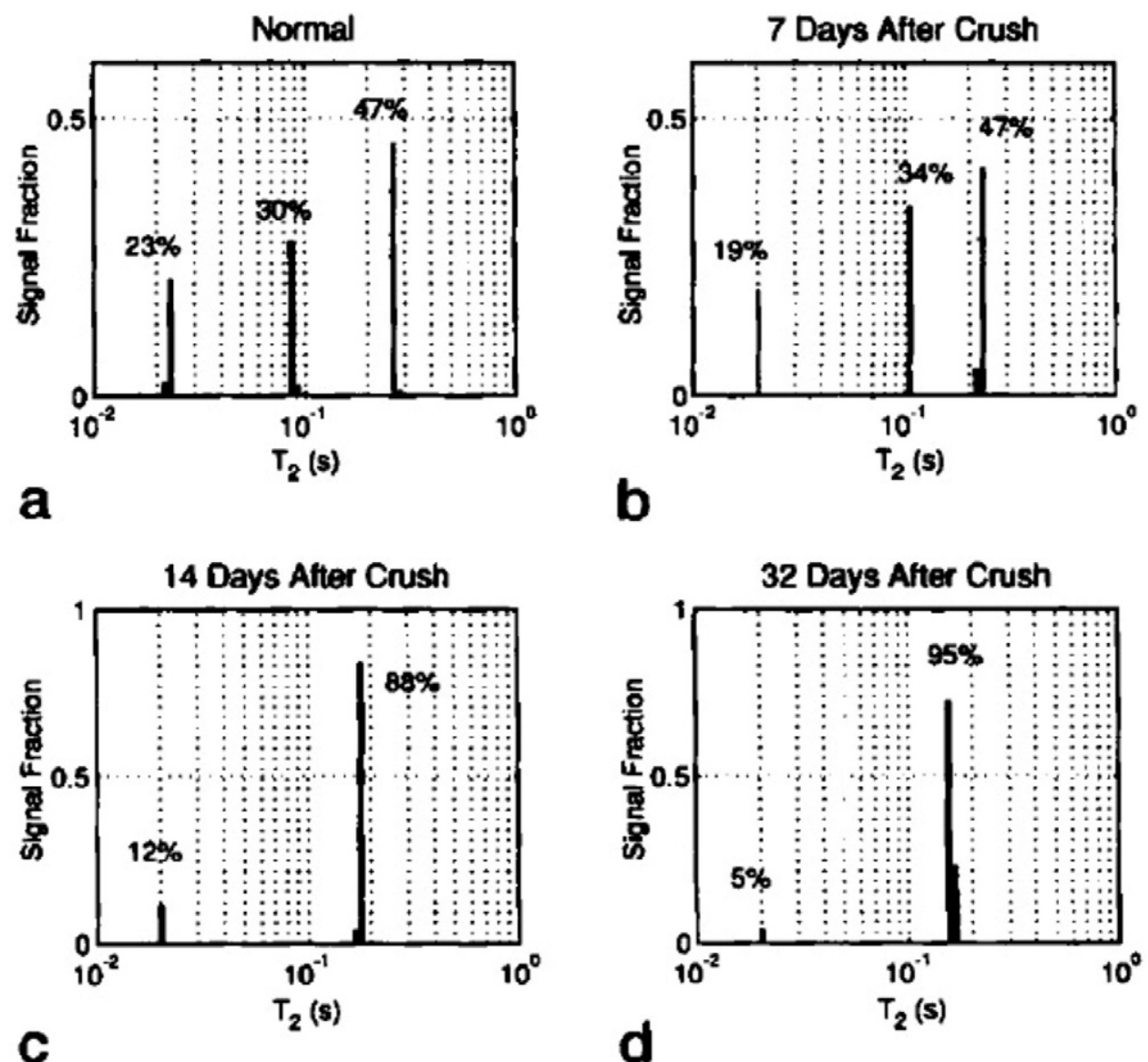

FIG. 3. $T_{2}$ distribution from peripheral nerve for (a) normal, (b) 7 days after crush injury, (c) 14 days after crush injury, and (d) 32 days after crush injury. ${ }^{60}$ (Reprinted from Magnetic Resonance in Medicine, Does MD, Snyder RE. Multiexponential T2 relaxation in degenerating peripheral nerve. Vol. 35, No. 1, 1996, pgs 207-213. Copyright 1996, with permission of Wiley-Liss, Inc., a subsidiary of John Wiley \& Sons, Inc.)

water pools were extracellular, axoplasmic, and myelin water. Authors Does et al. ${ }^{54}$ have since conducted a number of studies investigating frog sciatic nerve also using multi-echo MR. In 1995 they demonstrated in vivo three $\mathrm{T}_{2}$ relaxation components: 1$)$ myelin (19 $\mathrm{ms}, 26 \%$ ), 2) axon (63 ms, 29\%), and 3) connective tissue water (241 ms, 45\%). ${ }^{54}$ This longest $\mathrm{T}_{2}$ component had previously only been identified in vitro. ${ }^{53,55}$

A second study by Does et al. ${ }^{45}$ investigated the $T_{1}$, $\mathrm{T}_{2}$, and MTR properties of frog sciatic nerve at 3 Tesla (3T). Here the authors demonstrated that in addition to multiexponential $\mathrm{T}_{2}$ relaxation, each $\mathrm{T}_{2}$ component had its own $T_{1}$ relaxation and magnetization transfer (MT) properties providing further support for the assignment of these components to unique physical compartments of water. Surprisingly, similar MTR values were found for myelin water and axonal water; this was interpreted as having arisen from different magnetization exchange rates and $T_{1}$ relaxation times for the two environments. Therefore, similar MTRs do not necessarily indicate similar myelination states. The authors warned that "interpreting changes in MTR solely to reflect a change in degree of myelination could lead to erroneous conclusions."

Myelination has been shown to result in decreased $T_{1}$ and $\mathrm{T}_{2}$ in PNS tissue. ${ }^{56}$ This decrease was attributed to the interaction of water with myelin lipids. In garfish, the lipid content of the unmyelinated olfactory nerves was higher than that in the myelinated cranial nerves; however, the $T_{1}$ and $T_{2}$ times were longer in the unmyelinated nerves. ${ }^{56}$ The lipid composition was not analyzed and this may be important, because in model membranes, galactocerebroside was found to be a particularly effective molecule at reducing $T_{1}$ and $T_{2}$, presumably due to its large head group with four hydroxyl groups. ${ }^{57}$ The WC was similar for both types of nerves; therefore, the interactions with water molecules inside compartments may be important in determining relaxation times.

One of the earliest studies to examine peripheral nerve degeneration using nuclear MR was conducted by Jolesz et al. $^{58}$ in 1984. In this study, Wallerian degeneration was induced in rat sciatic nerve. Prolonged $\mathrm{T}_{1}$ and $\mathrm{T}_{2}$ relaxation times were observed in the excised injured nerve, accompanied by an increase in WC, as well as decreased myelin 
content on histology. Their results demonstrated the ability of MR to detect secondary changes in myelinated nerve fibers, and the authors hypothesized that it should be possible to detect Wallerian degeneration on MR scans. Several years later, Titelbaum et al. ${ }^{59}$ studied peripheral nerve injury in vivo in a series of animals also to investigate the role of MR in Wallerian degeneration. High-signal intensity was observed along the injured nerve, which corresponded to edema and myelin breakdown from Wallerian degeneration. The authors suggested that the duration and extent of signal abnormality might indicate the severity of the nerve injury.

In a crush injury model for Wallerian degeneration, Does and Snyder ${ }^{60}$ found that as degeneration progressed, a reduction in the fraction of the shortest $\mathrm{T}_{2}$ component was observed and attributed to a combination of interstitial edema and myelin loss. Subsequently, the $T_{2}$ spectra evolved from three distinct peaks to one which was hypothesized to arise from the collapse and loss of myelinated fibers. ${ }^{60}$ Figure 3 shows the evolution of the $T_{2}$ spectrum after a crush injury in the experiment by Does et al. ${ }^{60}$ In the injured rat peripheral nerve, the size of the short $\mathrm{T}_{2}$ component was correlated with a quantitative histological assessment of myelin during myelin loss and repair. ${ }^{61}$ However, the short $T_{2}$ component was unable to distinguish between intact myelin and myelin debris, and instead it represented all myelin present in the sample. ${ }^{61}$

Experiments in peripheral nerve continue to play a role in the study of myelin. Recently, Wessig et al. ${ }^{62}$ reported on a study in which lysolecithin, which focally dissolves myelin sheaths while sparing axons, was injected into the sciatic nerve of 30 male rats and imaged using conventional MR and $\mathrm{Gad}_{1}$, as well as with a novel micellar contrast agent gadofluorine $\mathrm{M}$ (Gf). Conventional MR and Gad $\mathrm{T}_{1}$ did not identify regions of demyelination, whereas $G f \mathrm{~T}_{1}$ images distinctly highlighted areas of focal demyelination that remained until remyelination occurred. This novel contrast agent may provide a new method of imaging focal areas of demyelination in vivo.

\section{HISTOLOGICAL VALIDATION STUDIES}

Although great effort has been put into finding a myelinspecific MR marker, pathological validation of any technique claiming to be such a marker is also necessary. However, pathological MR comparison studies are technically challenging and sometimes difficult to interpret. Tissue begins to degrade due to autolysis immediately upon death, often making it difficult to replicate in vivo MR measurements. Also, extensive tissue processing occurs in preparation for the application of histological stains that can change the shape of the tissue sample from the time it underwent MR, making subsequent comparisons difficult. Other limitations in histological staining include challenges in obtaining staining homogeneity and consistency; however, new antigen specific stains may make comparison across samples more quantitative. Also, some methods for quantifying pathological stains, such as manual cell-counting, can be labor intensive and prone to error. New methods such as optical density or automated counting may be beneficial. Another problem arises from the differences in slice thickness with the lower limit of MR resolution, being typically on the order of $1 \mathrm{~mm}$, whereas histopathology slices are typically 3 microns to 10 microns thick, creating partial volume effects. Because of these obstacles, only a relatively small number of studies have quantitatively investigated the correlation between MR-derived measures and histopathology.

\section{Magnetization transfer ratio, $T_{1}$ and $T_{2}$ relaxation}

Pioneering studies by Dousset et al. ${ }^{63,64}$ in both primates and guinea pigs, respectively, found that the MTR was only slightly reduced in edematous lesions (5\% to $8 \%$ ), whereas a much more dramatic decrease was observed in areas of demyelination (26\%). In a rat model, demyelinating and remyelinating corpus callosum lesions showed a good correlation between the MTR and myelin damage and repair as measured by histology. ${ }^{65}$ The MTR histogram parameters were also found to correlate with histopathological results including the myelination state. ${ }^{66}$ However, other pathological conditions may be responsible for a decrease in MTR, as was demonstrated by both Brocet et al. ${ }^{67}$ and Gareau et al., ${ }^{28}$ who showed a reversal of MTR decreases due to modulation of inflammation after inducing experimental autoimmune encephalomyelitis (EAE) in the guinea pig brain. Furthermore, Cook et al., ${ }^{68}$ using an EAE model in guinea pigs, found equal reductions in MTR in areas of edema compared to areas of demyelination in the spinal cord. Also, in a very recent study, Blezer et al. ${ }^{69}$ examined an EAE model in the marmoset brain comparing $\mathrm{T}_{1}$, $\mathrm{T}_{2}$ (5 echo, monoexponential fit) and the MTR to axonal density and macrophage count of both early active and inactive macrophages. The MTR was found to correlate significantly with the number of inactive macrophages $\left(R^{2}=0.26\right)$, as well as with the macrophage inflammation index, which reflects whether macrophages in the lesions express markers of active or inactive lesions $\left(R^{2}\right.$ $=0.49$ ), further supporting the possible influence of inflammation and presence of macrophages on the MTR.

The $\mathrm{T}_{2}$ measurements from animal models in the CNS tissue have also shown the $\mathrm{T}_{2}$ distribution to be multicomponent. ${ }^{15,70,71}$ Stewart et al. ${ }^{15}$ studied the $\mathrm{T}_{2}$ relaxation behavior of the spine and brain from guinea pigs induced with EAE. This was the first study to investigate $\mathrm{T}_{2}$ relaxation in the spinal cord, and they found decreases in the short $\mathrm{T}_{2}$ component consistent with histologically measured myelin loss. Decreased MWF levels after spinal cord injury also have been detected in rats. ${ }^{72}$ The relationship between the short $T_{2}$ component and myelin 
was also studied by Pun et al. ${ }^{73}$ and Odrobina et al. ${ }^{74}$ They examined the effect of demyelination induced by tellurium on the sciatic nerve of rats, with both MR and histology. Tellurium-treated animals showed a $68 \%$ decrease in healthy myelin in the sciatic nerve and a $45 \%$ increase in the extracellular matrix. A decrease in the area of the short $\mathrm{T}_{2}$ component, an increase in average $\mathrm{T}_{1}$, and an increase in the $\mathrm{T}_{2}$ of the intermediate component were also measured. A good correlation was observed between the degree of myelin staining and the size of the short $\mathrm{T}_{2}$ component $\left(R^{2}=0.59\right)$, whereas $\mathrm{T}_{1}$ was found to strongly correlate with the size of the extracellular matrix $\left(R^{2}=0.85\right)$. The authors postulated that the area of the short $\mathrm{T}_{2}$ component was the best measure of the process of demyelination.

Examining MTR and $\mathrm{T}_{2}$ relaxation measures in an EAE model of the guinea pig, Gareau et al. ${ }^{28}$ showed both measures were reduced in the normal-appearing white matter (NAWM). However, the MTR and myelin water appeared to be influenced by different aspects of EAE, as modulating the inflammation strongly influenced the MTR but did not affect the myelin water. This result suggests that the short $\mathrm{T}_{2}$ component is specific for myelin, whereas pathological features other than myelin content may be important in the interpretation of MTR. ${ }^{28}$ In another study, tumor necrosis factor- $\alpha$ was injected into rat sciatic nerve to induce inflammation with little demyelination and axonal loss. ${ }^{71}$ The MTR and the quantitative MT measure of the semi-solid pool size, $\mathrm{M}_{0 \mathrm{~B}}$, were found to decrease, whereas the average $T_{1}$ and $\mathrm{T}_{2}$ relaxation times increased. All of these MR measures correlated well with the extracellular volume of the neural tissue as evaluated by quantitative histology. Stanisz et al. ${ }^{71}$ also found that multicomponent $\mathrm{T}_{2}$ was the best at distinguishing between inflammation and demyelination, whereas MT measurements were more likely to be influenced by both changes in myelin and $\mathrm{pH}$.

A limited number of studies have also investigated MR histopathologic correlations in human tissue. In a fairly large study of samples collected from 17 multiple sclerosis (MS) subjects immediately postmortem, van Waesberghe et al. ${ }^{75}$ examined MTR and $\mathrm{T}_{1}$ contrast ratio (i.e., signal intensity of lesions relative to NAWM on a $\mathrm{T}_{1^{-}}$ weighted image) compared to axonal and myelin density. MTR and $T_{1}$ contrast ratio were found to correlate strongly with axonal density in lesions $\left(R^{2}=0.69\right.$ and 0.55 , respectively), and MTR also correlated strongly with axonal density in NAWM $\left(R^{2}=0.58\right)$, whereas the correlation of MTR and $\mathrm{T}_{1}$ contrast ratio with myelin density was much weaker $\left(R^{2}=0.20\right.$ and 0.36 , respectively). Schmierer et al. ${ }^{14}$ also compared MTR and $\mathrm{T}_{1}$ in fresh postmortem brain tissue from 20 subjects to measures of myelin content, axonal density, and gliosis. Both MTR and $\mathrm{T}_{1}$ were found to correlate with both myelin content and axonal density $\left(R^{2}=0.70\right.$ and 0.44 , respec- tively for MTR; $R^{2}=0.49$ and 0.24 , respectively for $\mathrm{T}_{1}$ ). Using multiple regression analysis, the primary MR correlate of myelination appeared to be MTR. No correlation was observed between either MR measure or gliosis. However, the authors do caution that "despite the strong association shown between MTR and myelin content, abnormalities in the former should not be attributed solely to variations in the latter." Bot et al. ${ }^{76}$ investigated the relationship between MTR, $\mathrm{T}_{1}$, and $\mathrm{T}_{2}$ (4 echoes, monoexponential) and staining for myelin and axons in 13 samples of formalin-fixed cervical spinal cord at 4.7 T. All MR measures correlated well with staining for myelin $\left(R^{2}=0.59,0.58\right.$, and 0.50 for $\mathrm{T}_{2}, \mathrm{MTR}$, and $\mathrm{T}_{1}$, respectively) and less well with axonal density $\left(R^{2}=\right.$ $0.19,0.17,0.15$ for $\mathrm{T}_{2}, \mathrm{MTR}$, and $\mathrm{T}_{1}$, respectively). The $\mathrm{T}_{2}$ was found to be the strongest independent predictor for myelin density. This was not found in an MS spinal cord study by Mottershead et al. ${ }^{13}$ in which the MTR, $\mathrm{T}_{1}$, and anisotropy were strongly correlated with myelin content, but $\mathrm{T}_{2}$ was more weakly correlated.

Studies in the human brain have shown postmortem formalin-fixed MR is comparable with in vivo imaging. ${ }^{77}$ Fortuitously, there is little change of the myelin water signal postmortem, both shortly after death in situ and on tissue fixation with formalin. ${ }^{78}$ The $\mathrm{T}_{2}$ distribution from the formalin-fixed brain is qualitatively similar to that from the brain in vivo, although quantitatively the $T_{2}$ is shifted to shorter times. A good qualitative correspondence was observed between myelin water in the formalin-fixed brain and the anatomic distribution of myelin ${ }^{79}$ as indicated by Luxol fast blue, a stain originally introduced by Klüver and Barrera $^{80}$ in 1953, and widely believed to stain phospholipid components of myelin. ${ }^{81-83}$ A good quantitative correlation between MWF and Luxol fast blue optical density was also observed across 25 samples from the MS brain (average, $\left.R^{2}=0.67\right) .^{78}$

A few studies have investigated the relationship between signal intensity and myelination. In a demyelinating model of rabbit sciatic nerve, Teresi et al. ${ }^{84}$ compared image intensity of $T_{1}$ and heavily $T_{2}$-weighted images to staining for myelin and glial cells. Different stages of demyelination were identified, each with their own MR properties. Early nerve degeneration exhibited demyelination with corresponding signal increase on the heavily $\mathrm{T}_{2}$-weighted sequence; however, no increase in glial cells or changes on the $T_{1}$ image was observed. Advanced nerve degeneration, which displayed an increase in glial cells but no further increase in demyelination, showed a corresponding decreased intensity on $\mathrm{T}_{1}$-weighted images, as well as a previously observed increase in $T_{2}$ intensity. The authors suggested that MR was able to distinguish different stages of demyelination in degenerating nerves. Using $\mathrm{T}_{1}$-weighted images, van Walderveen et al. ${ }^{85}$ and Bitsch et al. ${ }^{86}$ found that hypointense $\mathrm{T}_{1}$ MS lesions (also known as " $\mathrm{T}_{1}$ black holes") 
were correlated with the degree of tissue loss, although correlation with axonal count was most significant. However, the evolution of the hypointensity of the lesion was determined not only by axonal loss, but also by the demyelinating activity with remyelination, causing lesions to become less hypointense. ${ }^{86}$ In a study of MS spinal cord, proton density (PD) and $\mathrm{T}_{2}$-weighted images obtained from high-resolution MR showed higher signal intensities in areas with lowest axonal density and myelin content. ${ }^{87,88}$ In a recent study from the same group, Bo et al. ${ }^{89}$ found that subpial cortical demyelination in MS was not associated with focal or diffuse WM abnormalities found on MR or by histology, suggesting that the presence of WM pathology does not predict cortical demyelination in a clinical setting.

\section{Diffusion}

An extensive number of studies investigating diffusion measures in animal models have been completed by Song et al. ${ }^{22,23,90}$ and Sun et al. ${ }^{91-94}$ In 2002, this group studied dysmyelination in vivo using diffusion tensor imaging in the shiverer mouse, ${ }^{23}$ a mutation characterized by an almost total lack of CNS myelin, with MBP in particular being undetectable. They observed increases (relative to agematched controls) of the water diffusivity perpendicular to the axonal fiber tracts $\left(\lambda_{\perp}\right)$ in accordance with lack of myelin, whereas the diffusivity parallel to the axon $\left(\lambda_{\|}\right)$ remained unaffected, consistent with axonal preservation. The presence of incomplete myelination with intact axons was confirmed by electron microscopy, and the authors hypothesized that $\lambda_{\perp}$ and $\lambda_{\|}$may be able to differentiate myelin and axonal loss. This hypothesis was supported by work from the same group in which $\lambda_{\perp}$ and $\lambda_{\|}$from the mouse optic nerve with retinal ischemia was examined. ${ }^{22} \mathrm{In}$ the early stages of ischemia, $\lambda_{\|}$was found to decrease, consistent with the observed histological findings of axonal degeneration, whereas $\lambda_{\perp}$ and myelin content were unaffected. The $\lambda_{\perp}$ was then found to increase in the following days due to myelin degeneration, confirmed by histology. Song et al. ${ }^{90}$ and Sun et al. ${ }^{92}$ also examined the cuprizone model of demyelination and remyelination in the corpus callosum of the mouse brain, and they found that increases and decreases in $\lambda_{\perp}$ corresponded to the time course of demyelination and remyelination, respectively, as measured by histology. In the myelin-deficient rat spinal cord, $\lambda_{\perp}$ and $\lambda_{\|}$were higher, whereas FA was the same compared with normal rats, ${ }^{95}$ suggesting that myelin had an effect on the diffusion characteristics of water in WM, but not on the FA. Interestingly, formalin fixation appeared to have little effect on $\lambda_{\perp}$ in mouse brain, supporting the use of diffusionhistology comparisons to gain insight into the underlying mechanisms of observed diffusion measures. ${ }^{91,93}$ The use of $\lambda_{\perp}$ has subsequently been applied to the study of myelin in animal models of various diseases and injury, including Alzheimer's disease, ${ }^{94}$ weight-drop injury in the spinal cord, ${ }^{96} \mathrm{EAE}$ of the spinal cord, ${ }^{97}$ and herpes simplex infection of the CNS. ${ }^{98}$

Measures of diffusion have also been correlated with histological measures of axonal density and myelin content in human tissue. Mottershead et al. ${ }^{13}$ obtained quantitative MR maps of PD, $\mathrm{T}_{2}$ (2 echo, monoexponential fit), $T_{1}, M T$, and diffusion weighting from fresh postmortem spinal cord from four MS subjects at 7 Tesla (7T). Regions of interest were mapped by eye to histology images stained for axons and myelin. A correlation was detected between axonal density and MTR, PD, $\mathrm{T}_{1}$, and the diffusion standard deviation index (SDI, a measure of diffusion anisotropy) $\left(R^{2}=0.61,0.42,0.38\right.$, and 0.37 , respectively). Weaker correlations were found for axonal density and $\mathrm{T}_{2}\left(R^{2}=0.20\right)$. A correlation was also detected between myelin content in MS WM and $\mathrm{T}_{1}$, $\mathrm{PD}, \mathrm{MTR}, \mathrm{T}_{2}$ and SDI $\left(R^{2}=0.61,0.52,0.42,0.32,0.26\right.$, respectively). A weaker correlation was found between myelin content and $\langle D\rangle\left(R^{2}=0.20\right) .{ }^{13}$ A recent study by Schmierer et al. ${ }^{99}$ investigated the relationship between the diffusion measures of $\langle D\rangle$ and FA in the fresh postmortem brain with myelin content, axonal density, and gliosis. Both FA and $\langle D\rangle$ were found to correlate with both myelin content and axonal count $\left(R^{2}=0.62\right.$ and 0.49 , respectively for FA, and $R^{2}=0.46$ and 0.44 , respectively for $\langle D\rangle$ ). A weaker correlation was observed for both FA and $\langle D\rangle$ and gliosis $\left(R^{2}=0.25\right.$ and 0.30 , respectively). However, multiple regression analysis suggested $\langle D\rangle$ and FA were primarily affected by myelin content, whereas their correlation with axonal count was largely explained by the stronger association of the latter with myelin content.

\section{Summary}

The MTR has shown a correlation with myelination, but was influenced by inflammation, axonal density, and the presence of macrophages. The MWF was well correlated with myelin content both in animal and MS studies. The diffusion metrics, $\langle D\rangle$, and FA were related to myelin content, and $\lambda_{\perp}$ changed with myelination state. Tables 1 and 2 summarize all of the correlations between histology and the various MR measures as previously reported.

\section{NORMAL MYELINATION}

In humans, myelination begins in the fifth fetal month, developing rapidly for the first 2 years, but continues throughout life until the sixth decade. ${ }^{100,101}$ Generally, myelination begins in posterior regions before anterior regions of the brain. ${ }^{102}$ Onset of myelination is accompanied by an increase in lipid and protein content and a corresponding decrease in WC. Decreases in $\mathrm{T}_{1}$ and $\mathrm{T}_{2}$ times of the developing brain have been significantly correlated with decreases in $\mathrm{WC}^{103}$; therefore, conventional MR of neonates usually assesses myelination us- 
TABLE 1. Comparison of Myelin Staining to Proton Density, $T_{l}$ Contrast Ratio (Signal Intensity of Lesions Relative to $N A W M$ on a $T_{1}$-weighted image), $T_{1}$ time, $\langle D\rangle$, and Diffusion Anisotropy

\begin{tabular}{|c|c|c|c|}
\hline MR Measure & $\mathrm{R}^{2}$ With Myelin Stain & Plot & Reference \\
\hline PD & 0.52 & $\mathrm{n} / \mathrm{a}$ & Mottershead et al. ${ }^{13}$ \\
\hline $\mathrm{T}_{1}$ contrast ratio & 0.36 & $\mathrm{n} / \mathrm{a}$ & Van Waesberghe et al. ${ }^{75}$ \\
\hline $\mathrm{T}_{1}$ time & 0.61 & $\frac{}{0.1}$ & Mottershead et al. ${ }^{13 \dagger}$ \\
\hline
\end{tabular}

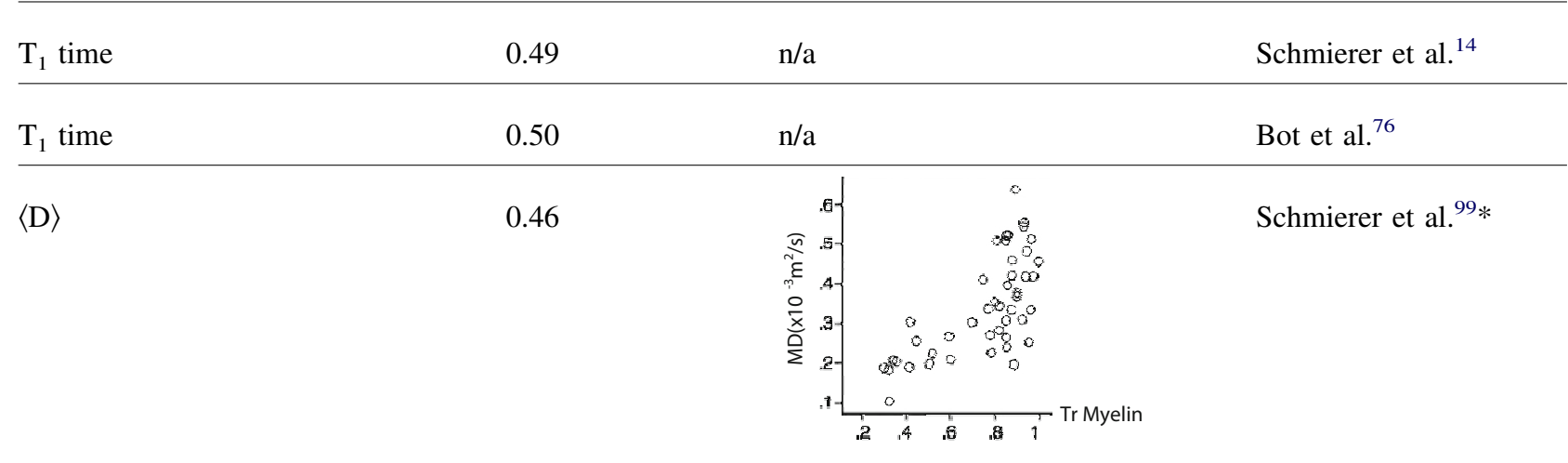

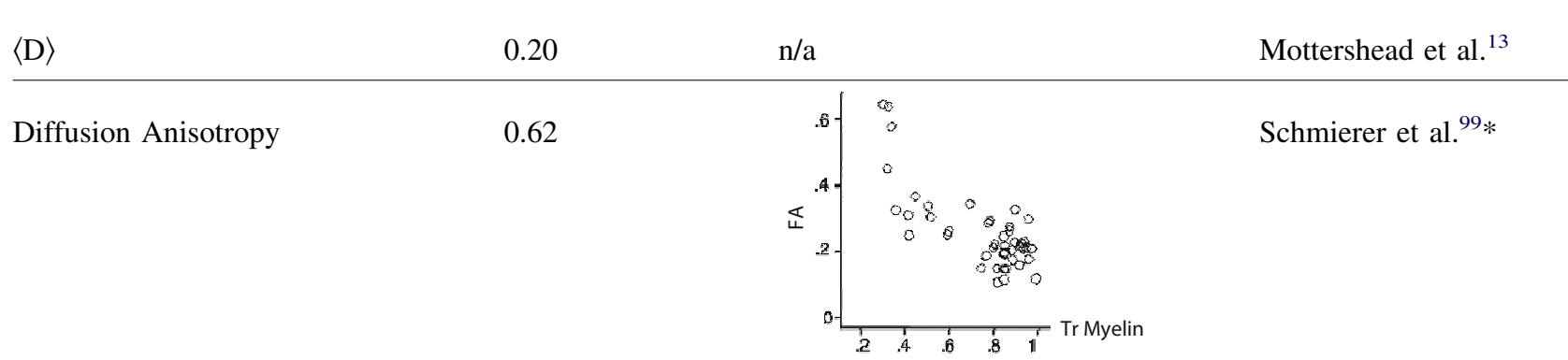

$\langle\mathrm{D}\rangle$, mean diffusivity; n/a, not available; NAWM, normal appearing white matter; PD, proton density.

*Reprinted from NeuroImage, 35(2), Schmierer K, Wheeler-Kingshott CA, Boulby PA et al., Diffusion tensor imaging of post mortem multiple sclerosis brain, pgs. 467-77, Copyright (2007), with permission from Elsevier.

${ }^{\dagger}$ Reprinted from Journal of Neurology, 250(11), Mottershead JP, Schmierer K, Clemence M et al., High field MRI correlates of myelin content and axonal density in multiple sclerosis-a post-mortem study of the spinal cord, pgs. 1293-1301, Figure 4, Copyright 2003 with kind permission of Springer Science and Business Media.

ing $\mathrm{T}_{1}$-weighted and $\mathrm{T}_{2}$-weighted images. On $\mathrm{T}_{1^{-}}$ weighted images, the $\mathrm{WM}$ of the newborn brain is hypointense compared with the GM, with the exception of a few regions (e.g., posterior internal capsule) that are hyperintense, presumably due to early myelination. During the next 8 months to10 months, WM becomes completely hyperintense relative to GM. ${ }^{104}$ On $\mathrm{T}_{2}$-weighted spin echo images, newborn WM is hyperintense com- pared with GM, except, again for small regions such as the posterior internal capsules. During the next 30 months, the WM slowly becomes hypointense leading to the normal gray/white contrast observed in the adult brain. ${ }^{104}$

In the developing brain, $\langle D\rangle$ was found to decrease in central WM, but not in the posterior internal capsules, even with ongoing myelination, suggesting that $\langle D\rangle$ is largely 
TABLE 2. Comparison of Myelin Staining to $T_{2}$ Time, MTR, and MWF

\begin{tabular}{|c|c|c|c|c|}
\hline MR Measure & $\mathrm{R}^{2}$ With Myelin Stain & & Plot & Reference \\
\hline $\mathrm{T}_{2}$ (4 echoes, mono-exponential) & 0.59 & 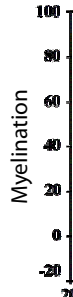 & 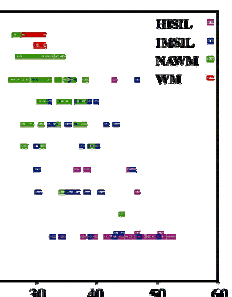 & Bot et al. ${ }^{76} *$ \\
\hline
\end{tabular}

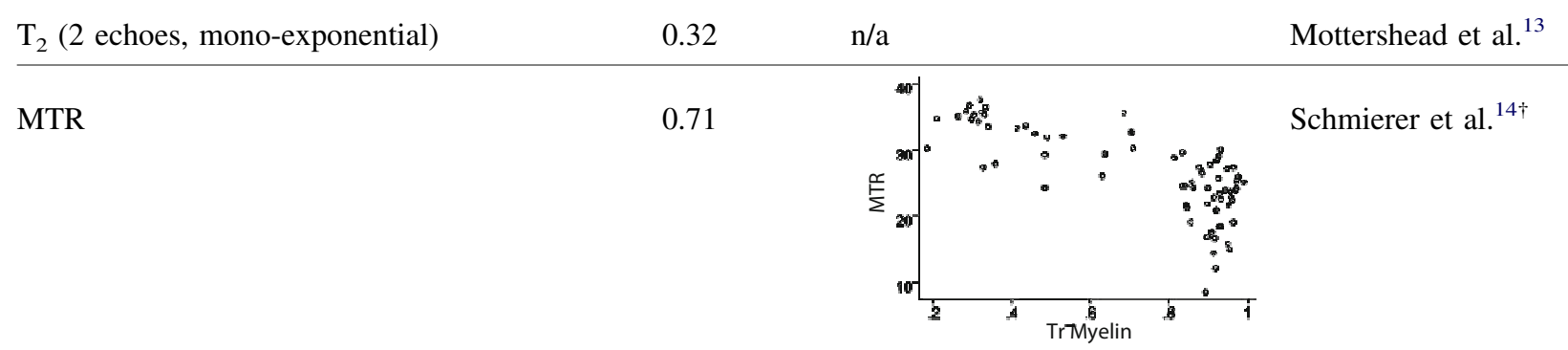

$\begin{array}{lccc}\text { MTR } & 0.20 & \text { n/a } & \text { Van Waesberghe et al. }^{75} \\ \text { MTR } & 0.58 & \text { Bot et al. } & \\ \text { MTR } & 0.42 & \text { Mottershead et al. }^{13} \\ \text { MWF (2500 echoes, multi-exponential) } & 0.56 & \text { Webb et al. }^{61 \ddagger}\end{array}$

MWF (32 echoes, multi-exponential)

0.67

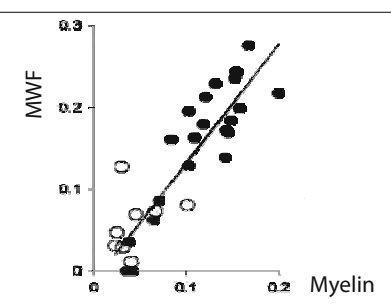

Laule et al. ${ }^{78 \S}$

HISIL, high-signal-intensity lesions; IMSIL, intermediate-signal-intensity lesions; MTR, magnetization transfer ratio; MWF, myelin water fraction; n/a, not available; NAWM, normal appearing white matter; WM, white matter.

*Reproduced from Radiology, 233, Bot JC, Blezer EL, Kamphorst W, et al., The spinal cord in multiple sclerosis: relationship of high-spatial-resolution quantitative MRI findings to histopathologic results, pgs. 531-540, Copyright 2004, with permission from the Radiological Society of North America.

${ }^{\dagger}$ Reproduced from Annals of Neurology, Schmierer K, Scaravilli F, Altmann DR, et al., Magnetization transfer ratio and myelin in postmortem multiple sclerosis brain, Vol. 56, No. 1, 2004, pgs. 407-415. Copyright 2004, with permission of Wiley-Liss, Inc., a subsidiary of John Wiley \& Sons, Inc.

${ }^{\ddagger}$ Reproduced from Magnetic Resonance in Medicine, Webb S, Munro CA, Midha R, Stanisz GJ. Is multicomponent T2 a good measure of myelin content in peripheral nerve? Vol. 49, No. 1, 2003, pgs. 638-645. Copyright 2003, with permission of Wiley-Liss, Inc., a subsidiary of John Wiley \& Sons, Inc.

${ }^{\S}$ Reproduced with permission from Laule C, Leung E, Li DK, et al., Myelin water imaging in multiple sclerosis: quantitative correlations with histopathology. Mult Scler. 2006;12:747-753. Copyright (@Sage Publications, 2006), by permission of Sage Publications Ltd. 

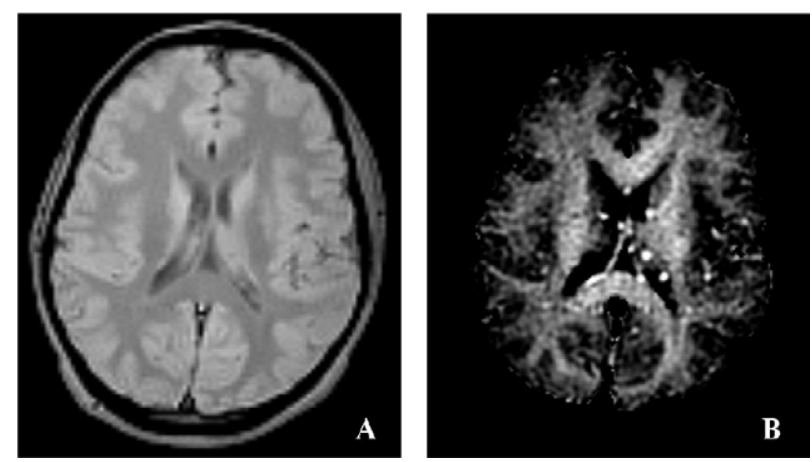

FIG. 4. (A) Proton density and (B) myelin water map from a normal control. (Courtesy of Field A, Wu Y, Samsonov A, and Alexander A, [Wisconsin]).

dependant on axonal growth. ${ }^{105}$ Futhermore, $\langle D\rangle$ was found to drop by more than $25 \%$ during the first 3 months to 4 months of life and reached adult values by approximately 3 years of age, ${ }^{106}$ even though the brain is known to continue myelinating for several decades after birth. ${ }^{100,101}$ In children greater than 1 year of age, the fractional anisotropy began increasing and continued increasing into the second decade of life. ${ }^{107}$ The change in FA with age may reflect a combination of the compacting of neurons into fiber tracks, increased myelin content, and decreased WC, all of which lead to more restricted diffusion. It should also be noted that detectable FA in the posterior internal capsule was observed at 26 weeks of gestational age, even with no myelin present. ${ }^{108}$ Prayer et al. ${ }^{109}$ found in a study of premyelinated rat pup nerves that inhibiting sodium channel pumps caused a loss of diffusion anisotropy, suggesting yet another mechanism for anisotropy in axons. In a very recent study, Ashtari et al. ${ }^{110}$ examined two groups of late adolescent males and found no changes in $\lambda_{\perp}$, but they did find increases in FA and $\lambda_{\|}$between the ages of 16 and 18.2 years. The authors hypothesize that normal brain development during late adolescence is more strongly influenced by increased axonal fiber organization and reduction of tortuousity toward more straightened fibers than axonal myelination. In the aging adult brain, FA has been found to decrease with age in WM. ${ }^{111-114}$ The reduction in FA was observed to be linear from approximately 20 years old, it was concentrated in the frontal WM areas, ${ }^{111}$ and it was more dramatic for the genu compared to the splenium of the corpus callosum. ${ }^{112}$ Ota et al. ${ }^{112}$ also observed an increase in $\langle D\rangle$, as well as $\lambda_{\perp}$ with increasing age. Measures from DTI may represent different aspects of development because changes occurring in the brain structure at infancy are quite different from changes occurring in adulthood.

The MTR and MTR histogram peak location were found to increase with age, predominantly in the first 2 years of life to a value approximately double those observed in infancy. ${ }^{115,116}$ The observed increase over time was fit to a single exponential and was region-dependent. ${ }^{116}$ In the aging adult brain, Silver et al. ${ }^{117}$ found a weak inverse correlation between age and MTR $\left(R^{2}=\right.$ 0.09). A similar trend was found by Armstrong et al., ${ }^{118}$ but neither Rovaris et al. ${ }^{119}$ nor Mehta et al. ${ }^{120}$ found a correlation between the MTR and age. In adult WM, some groups ${ }^{25,117,118,120}$ have found small regional differences in the MTR and size of the restricted pool (F), but others have not. ${ }^{121,122}$

As neurons proliferate, $\mathrm{N}$-acetyl-aspartate has been observed to increase and choline-containing compounds (Cho) to decrease in the developing brain. ${ }^{123}$ The large amount of Cho present in early development is believed to be due to a large membrane turnover rate related to myelination. ${ }^{124}$ As myelination slows down, the area of the Cho peak decreases ${ }^{123}$ and much lower values of Cho are reported in the adult brain. ${ }^{125}$ Although several studies have found no correlation between Cho and age in the adult brain, ${ }^{126,127}$ one study found an increase in Cho with increasing age. ${ }^{128}$ Kreis et al. ${ }^{129}$ found a significant correlation between age and metabolite $T_{1}$ and $T_{2}$ relaxation times in healthy WM. In particular, they found that the $\mathrm{T}_{1}$ of both $\mathrm{N}$-acetyl-aspartate and creatine decreased with age, whereas the $\mathrm{T}_{2}$ of $\mathrm{N}$-acetyl-aspartate significantly increased. This was the first study to demonstrate a correlation between metabolite relaxation times and age in the adult brain, and this was previously only observed in the developing brain. ${ }^{123}$

In healthy controls, much larger MWFs have been observed in WM than GM, and MWF has also varied by more than a factor of 2 between different WM structures. ${ }^{30,35,48,122,130}$ The observed regional differences in MWF are hypothesized to be a result of differing regional myelin contents. Figure 4 shows an example of a myelin water map for a healthy control. A correlation between MWF of the frontal lobes and age (as well as years of education) has been observed in normals. ${ }^{131}$ Although MT has been cited as a measure for myelin, only a weak correlation exists between MWF and MTR. ${ }^{28,122}$ Figure 5 shows a comparison between $\mathrm{F}$ (data taken from reference 25), MTR, and MWF for various WM and GM structures. Note that MWF of GM is approximately $20 \%$ of WM, whereas MTR and F of $\mathrm{GM}$ are $87 \%$ and 53\% of WM, respectively. Figure 6 shows the relationship between MTR (data taken from reference 120) and $\mathrm{MWF}^{131}$ with age in frontal WM.

A number of studies investigating myelin in the spinal cord have also been done. The imaging of the spinal cord provides challenges due to the small diameter of the cord, magnetic field inhomogeneities, and the presence of flow from CSF, which causes motion and artifacts. $T_{2}$ studies have shown the feasibility of measuring MWF in the spinal cord in vivo. ${ }^{47,132,133}$ The MWF has been found to be approximately $50 \%$ higher in spinal cord than normal brain WM and is reported to vary along the length of the cord. ${ }^{132}$ Several spectroscopy studies have also demonstrated the feasibility of using MRS to study the spinal cord, ${ }^{134-136}$ 


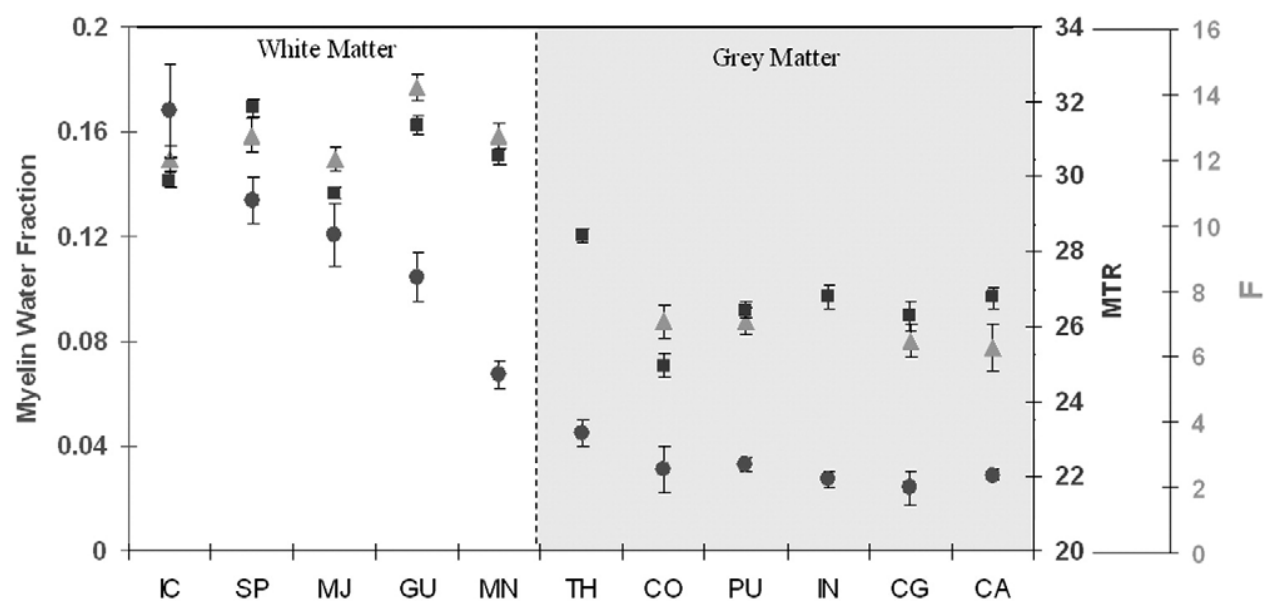

FIG. 5. Studies investigating the semi-solid pool (F, triangles) (data from Sled et al., ${ }^{25}$ 2004), magnetization transfer ratio (MTR, squares) and myelin water fraction (MWF, circles) for various white matter (WM) (internal capsule [IC], splenium [SP], major forceps [MJ], genu [GU], minor forceps [MN]) and gray matter (GM) (thalamus [TH], cortical gray [CO], putamen [PU], insular cortex [IN], cingulated gyrus [CG], and head of the caudate [CA]) structures in human healthy brain. Note that MWF of gray matter (GM) is approximately $20 \%$ of WM, whereas MTR and F of GM are $87 \%$ and $53 \%$ of WM, respectively.

although normative studies have yet to be done. Both MTR $^{137-140}$ and diffusion ${ }^{141-143}$ measures have also been examined in the normal spinal cord, although typically as a control for various disease studies and large normative studies that have not yet been completed.

\section{DEMYELINATION}

The ability to image myelin in vivo has widespread application in the study of neurodegenerative diseases, both from the aspect of gaining insight into disease processes, as well as monitoring clinical therapy. Demyelination refers to the loss or destruction of previously healthy myelin and a wide variety of existing demyelinating diseases and disorders. Filley ${ }^{144}$ presents an excellent review of many such disorders in a recent text, and here we will discuss two such diseases that include demyelination in their pathology.

\section{Multiple sclerosis}

Multiple sclerosis (MS) is an autoimmune disease of the CNS that is characterized by areas of focal, as well as diffuse, edema, inflammation, demyelination, and axonal loss. ${ }^{145}$ However, the mechanisms underlying the clinical evolution and ultimate progression of MS and their relationship to these pathological features are still poorly understood. Much of the pioneering work in attempting to image myelin with MR has been carried out in the field of MS. The initial focus on imaging myelin in MS was on the study of lesions, which are clearly visible with conventional imaging (bright on $\mathrm{T}_{2}$-weighted imaging, dark or gadolinium enhancing on $\mathrm{T}_{1}$-weighted imaging).
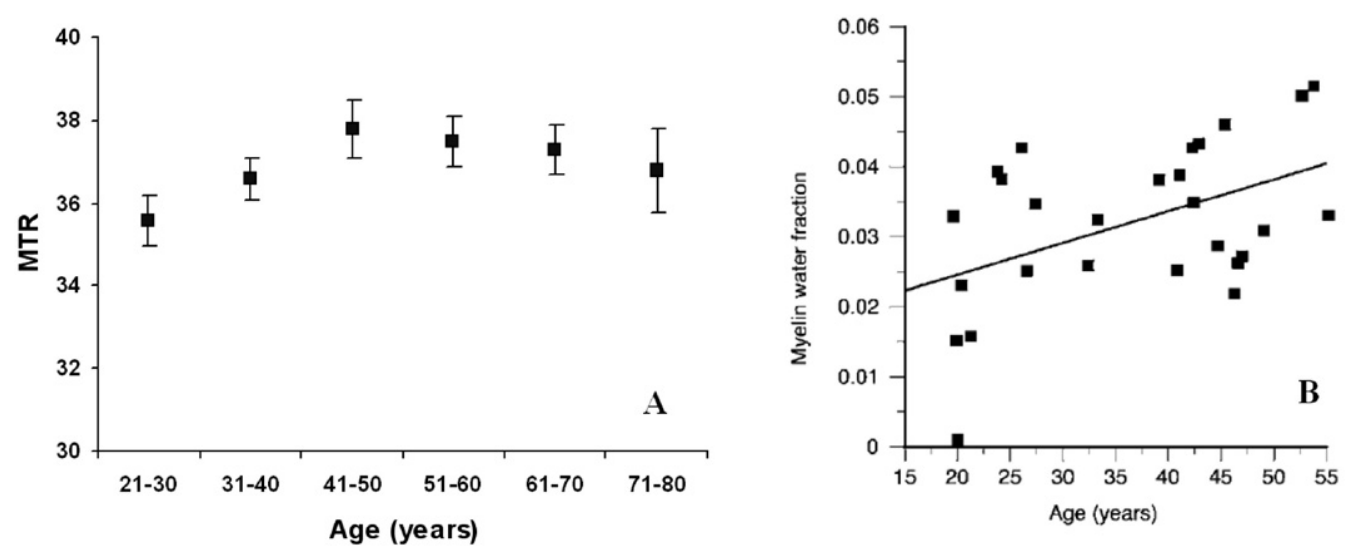

FIG. 6. (A) Magnetization transfer ratio (MTR) (data from Mehta et al., $\left.{ }^{120} 1995\right)$ and (B) myelin water fraction (MWF) (Flynn et al., ${ }^{131} 2003$, reprinted with permission from Macmillan Publishers Ltd: Molecular Psychiatry, Flynn SW, Lang DJ, Mackay AL, et al. Abnormalities of myelination in schizophrenia detected in vivo with MRI, and post-mortem with analysis of oligodendrocyte proteins. 2003;8:811-820, copyright 2003) in control frontal white matter versus age. The MWF shows a positive correlation with age $\left(R^{2}=0.22 ; p=0.012\right)$, whereas MTR does not. Rovaris et al. ${ }^{119}$ also did not find a correlation between whole brain MTR and age, but Silver et al. ${ }^{117}$ and Armstrong et al. ${ }^{118}$ did find a correlation. 
Table 3. Changes in MR Measures Influenced by Myelin Compared with Changes in Myelin as Measured by Histology*

\begin{tabular}{|c|c|c|c|c|c|c|c|c|c|c|c|}
\hline & $\begin{array}{c}\text { Myelin } \\
\text { (histology) }\end{array}$ & $\mathrm{T}_{1}$ & $\mathrm{~T}_{2}$ & MTR & F & FA & $\langle D\rangle$ & $\lambda_{\perp}$ & Lipid & Cho & MWF \\
\hline \multicolumn{12}{|l|}{ Myelination } \\
\hline Development & $\uparrow^{100}$ & $\downarrow^{103,104}$ & $\downarrow^{103,104}$ & $\uparrow^{115,116}$ & - & $\uparrow^{107}$ & $\downarrow^{105,106}$ & change $^{110}$ & - & $\downarrow^{123}$ & - \\
\hline Aging & $\uparrow^{101}$ & $\downarrow^{271}$ & $\begin{array}{c}\uparrow \text { then }(\mathrm{a} / \mathrm{f} \\
40 \mathrm{yr}) \\
\downarrow 271,272\end{array}$ & $\begin{array}{l}\uparrow 117,118 \\
\quad \text { or no } \\
\text { change }{ }^{119,120}\end{array}$ & - & $\downarrow^{111-114}$ & $\uparrow^{112}$ & $\uparrow^{112}$ & - & $\begin{array}{l}\uparrow^{128} \text { or no } \\
\text { change }^{126,127}\end{array}$ & $\uparrow^{131}$ \\
\hline $\begin{array}{l}\text { Demyelination } \\
\text { MS (lesion) }\end{array}$ & $\downarrow^{273}$ & $\uparrow^{274}$ & $\uparrow^{274}$ & $\downarrow^{122,153-158}$ & $\downarrow^{26,164}$ & $\downarrow^{146}$ & $\begin{array}{c}\uparrow{ }^{147,148,150} \text { or } \\
\text { no change }^{146}\end{array}$ & $\uparrow^{146}$ & $\uparrow^{166-168}$ & $\uparrow^{167-170}$ & $\downarrow^{46,122,130}$ \\
\hline$M S(N A W M)$ & $\downarrow^{178}$ & $\uparrow^{275}$ & $\uparrow^{276}$ & $\downarrow^{26,156,176,177}$ & $\downarrow^{46,165}$ & $\downarrow^{149}$ & $\uparrow^{148}$ & $\uparrow^{146,173}$ & $\uparrow^{169}$ & $\uparrow^{175}$ & 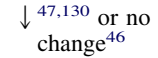 \\
\hline Alzheimer's disease & $\downarrow^{187,188}$ & - & $\uparrow^{189-192}$ & $\downarrow^{200,201}$ & - & $\downarrow^{193-196}$ & $\uparrow 193,194,196$ & $\uparrow^{197}$ & $\uparrow^{277}$ & $\begin{array}{l}\uparrow{ }^{278} \text { or no } \\
\text { change }^{279,280}\end{array}$ & - \\
\hline $\begin{array}{l}\text { Dysmyelination } \\
\text { Leukodystrophies }\end{array}$ & $\downarrow^{281}$ & $\uparrow^{282}$ & $\uparrow^{283}$ & $\downarrow^{198,216}$ & - & $\downarrow^{18,217-219}$ & $\underset{219}{\uparrow}$ or $\downarrow^{18,217-}$ & $\uparrow^{23,95}$ & $\begin{array}{l}\text { No change } 228 \\
\text { except } \\
\text { Zellweger } \\
\text { 227 }\end{array}$ & $\begin{array}{c}\uparrow^{220-223} \text { or } \\
\downarrow^{224-226}\end{array}$ & - \\
\hline$P K U$ & $\downarrow^{233}$ & - & $\uparrow^{235}$ & - & - & $\downarrow^{239}$ & $\downarrow^{217,235,238,240}$ & $\downarrow^{240}$ & no change ${ }^{234}$ & $\begin{array}{l}\downarrow \\
\downarrow^{235,236} \text { or nonge } \\
\text { chang,240 }^{237}\end{array}$ & $\downarrow^{234}$ \\
\hline Schizophrenia & $\downarrow^{242,243}$ & $\begin{array}{c}\uparrow^{284} \text { or no } \\
\text { change }^{285}\end{array}$ & 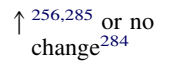 & $\downarrow^{252,257,258}$ & - & $\downarrow^{250-252}$ & $\uparrow^{253,254}$ & $\uparrow^{255}$ & $\uparrow 246,247$ & no change $e^{248,249}$ & $\downarrow^{131}$ \\
\hline Remyelination & $\uparrow^{273}$ & - & $\downarrow^{85,86,159,265}$ & $\uparrow 65,159$ & - & - & - & $\downarrow^{90,92}$ & $\downarrow^{169,266}$ & $\downarrow^{169,266}$ & $\uparrow^{61,267}$ \\
\hline
\end{tabular}

MTR, magnetization transfer ratio; F, the fraction of protons in nonaqueous tissue; FA, fractional anisotropy; $\langle\mathrm{D}\rangle$, mean diffusivity; $\lambda_{\perp}$, radial diffusivity; Cho, choline; MWF, myelin water fraction; MS, multiple sclerosis; MS NAWM, multiple sclerosis normal appearing white matter; PKU, phenylketonuria.

*The references quoted herein are purely representative examples and the summarized results are not an exhaustive search. 


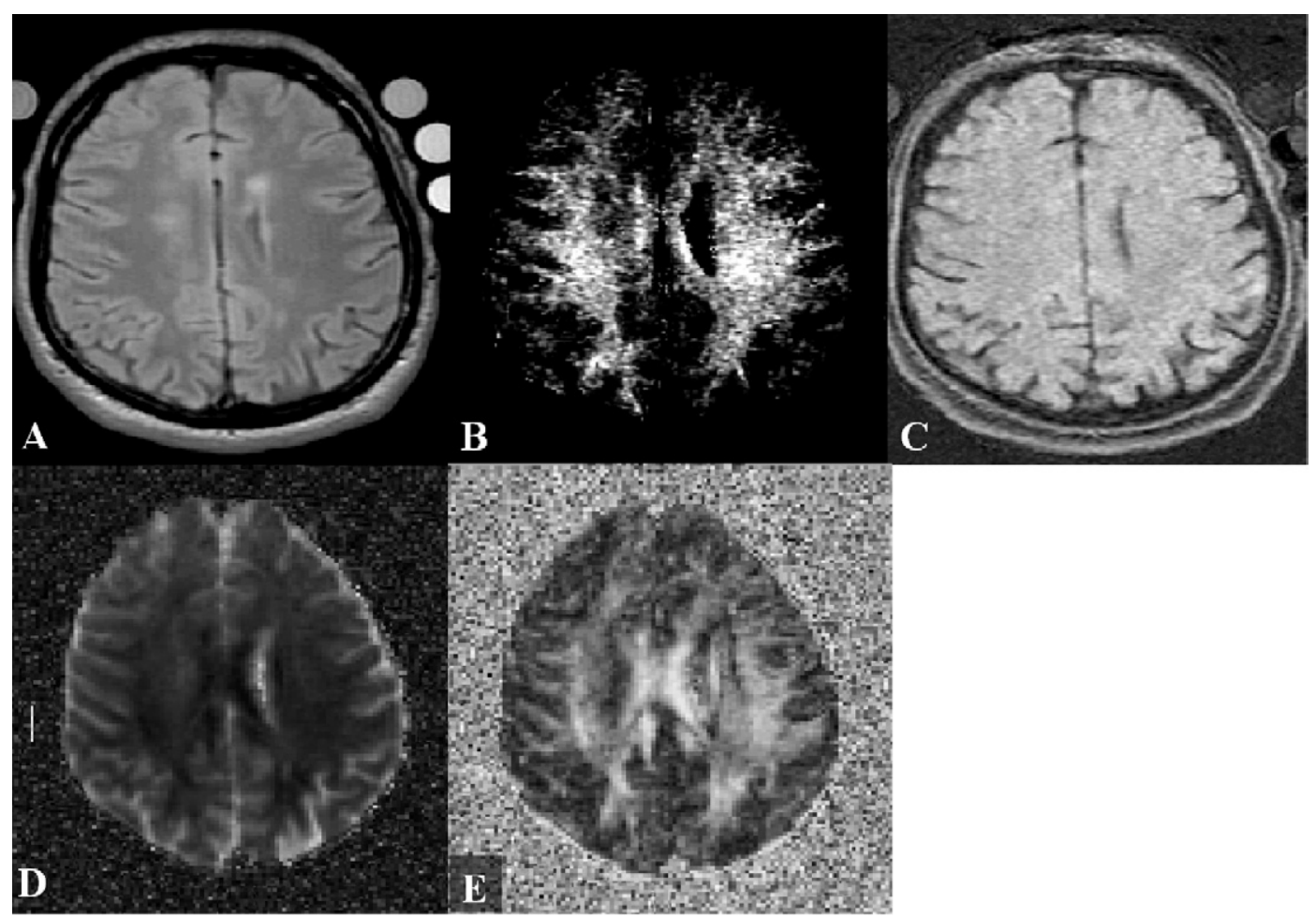

FIG. 7. (A) Proton density weighted image, (B) myelin water fraction map, (C) magnetization transfer ratio map, (D) $\lambda_{\perp}$ map, and (E) fractional anisotropy map for a patient with multiple sclerosis.

The MWF has been shown to be variably decreased in MS lesions, ${ }^{29,46,122,130}$ likely reflecting the different lesion pathology. A recent DTI study by Lin et al. ${ }^{146}$ examining lesions in the pyramidal tract found increased $\lambda_{\perp}$ and lower FA, but no abnormalities in $\lambda_{\|}$or $\langle D\rangle$ when compared to NAWM consistent with the removal of barriers perpendicular to the axon. In the brain ${ }^{147-150}$ and spinal cord, ${ }^{151,152}$ the less myelin-specific diffusion metrics, FA and $\langle D\rangle$, were also observed to be abnormal in MS lesions. The MTR has consistently been observed to be reduced by varying degrees in MS lesions. ${ }^{153-158}$ The $\mathrm{T}_{1}$ hypointense lesions, representing lesions with more severe tissue damage and axonal loss than $\mathrm{T}_{1}$ isointense lesions on postmortem studies, ${ }^{159}$ were found to have a greater reduction in MTR than $\mathrm{T}_{1}$ isointense lesions. ${ }^{160}$ Reductions in MTR have also been described to antedate the appearance of lesions on conventional MR, ${ }^{158,161-163}$ although whether these MTR changes arose from demyelination, inflammation, or a combination of both is still unclear. Quantitative MT (qMT) studies investigating F, which is partially made up of myelin, and the MT rate $\left(\mathrm{k}_{\mathrm{for}}\right)$, have found both measures to be decreased in MS lesions, ${ }^{26,46,164,165}$ attributed to changes in myelination. Magnetic resonance spectroscopy has detected a strong lipid peak in acute lesions attributed to myelin breakdown product during demyelination. ${ }^{166-168}$ Increases in Cho have also been seen in lesions ${ }^{167-170}$ and have been described to antedate lesion appearance on conventional MR. ${ }^{171}$ Such increases in choline may be related to in- creased turnover of choline-containing myelin membrane phospholipids and cellular inflammation.

In recent years, much effort has also been put into studying the normal-appearing WM in MS. The MWF of NAWM was found to be diffusely reduced in both the brain (by $16 \%$ ) $^{130}$ and the spinal cord (by $\left.\sim 25 \%\right)^{47}$ when compared to healthy controls. Fractional anisotropy was also reduced (by 4\%-11\%) and $\langle D\rangle$ increased (by $2 \%-3 \%$ in all cases except for $13 \%$ in reference 146) in NAWM, ${ }^{146,148,149,172}$ and recently an increased $\lambda_{\perp}$ was observed in NAWM ${ }^{146,173,174}$ by $4 \%$ to $20 \%$. Magnetic resonance spectroscopy of NAWM has found abnormalities that could be associated with myelin pathology. In NAWM, Narayana et al. ${ }^{169}$ observed the presence of lipid peaks, and increased myoinositol and choline have also been described in NAWM. ${ }^{175}$ Reductions in NAWM MTR (by 1.2\%-5.5\%) have been reported by many groups, ${ }^{26,156,158,176,177}$ as well as reductions in $\mathrm{F}$ using $\mathrm{qMT}^{46,165}$ by $11 \%$ to $14 \%$. All these findings are consistent with a decrease in the amount of myelin in MS normal-appearing WM.

These observed MR changes in NAWM are supported by histopathologic studies finding demyelination, ${ }^{178}$ as well as decreased myelin-associated glycoprotein immunostaining in WM that appeared normal with Luxol fast blue. ${ }^{179}$ An early study suggested that since myelin is rich in lipid, and makes up the majority of all lipid found in WM, total lipid determination could be used as a simple indicator for myelin. ${ }^{180}$ The NAWM showed a $15.5 \%$ reduction in total 
lipid when compared to control WM, suggesting a similar decrease in NAWM myelin. Several other studies have examined galactolipids, including cerebrosides, which are believed to be more directly related to myelin content and have found galactolipid decreases in NAWM of $13.5 \%{ }^{181}$ and $17 \%{ }^{182}$ when compared to control WM. The reduction in these biochemical markers of myelin has, in the past, been attributed to the inclusion of small plaques in the NAWM assayed. ${ }^{183}$ However, MR data, such as the aforementioned studies, would suggest that such findings might also be due to a more diffuse reduction of nonlesional myelin in NAWM. This diffuse myelin loss could be due to concomitant loss of axons in Wallerian degeneration as reported in NAWM. ${ }^{184-186}$ Table 3 summarizes myelinrelated MR changes observed in MS and Figure 7 shows an example of a PD-weighted image, myelin map, MTR map, FA map, and $\lambda_{\perp}$ map for an MS subject.

Because MS is a complex disease characterized by many different types of pathology, it is important to consider other possible sources for changes in MR markers claiming to be specific for myelin. Changes in WC arising from inflammation or edema can strongly influence diffusion parameters and MTR. The MWF is also influenced by $\mathrm{WC}$, as this measure is a ratio of the myelin water signal to the total signal from all water; hence decreases in MWF could arise from increases in WC. However, a recent model showed that the observed increases in WC in MS should only result in a small decrease in MWF. If the MWF decreases observed in lesions and NAWM were to have occurred purely due to increases in WC, the volume increases would be larger than $15 \%$ making this scenario unrealistic. ${ }^{130}$ Nevertheless, small changes in MWF can certainly, at least in part, arise from an increase in WC. Similarly, MRS metabolites would also be diluted by an increase in WC.

\section{Alzheimer's disease}

Alzheimer's disease (AD) is the most common form of dementia, typically affecting the elderly, and it is characterized by short-term memory loss, confusion, emotional instability, and progressive loss of mental ability. Alzheimer's disease is a neurodegenerative disorder that results in loss of neurons and subsequent loss of axons and myelin. In $\mathrm{AD}$, histological studies have demonstrated a widespread decrease in myelin that has been observed in NAWM, as well as more severe myelin loss in focal regions. ${ }^{187,188}$ Numerous studies have measured the $\mathrm{T}_{2}$ (either $2^{189-191}$ or 7 echoes ${ }^{192}$ ) in patients with AD and have found increases in some WM areas compared to controls. Iron, which decreases $\mathrm{T}_{2}$, is found in oligodendrocytes, and therefore the increase in $\mathrm{T}_{2}$ has been attributed to a lower iron concentration due to a loss of oligodendrocytes and consequently myelin. ${ }^{192}$ Using diffusion tensor imaging, $\langle D\rangle$ was found to be increased, and fractional anisotropy decreased in AD. ${ }^{193-196}$ The $\lambda_{\perp}$ was also observed to be increased in AD frontal WM, attributed to a decrease in myelin. ${ }^{197}$ No difference was found between $\mathrm{AD}$ patients and controls when measuring global brain MTR ${ }^{198,199}$; however a decrease in AD WM MTR was observed. ${ }^{200,201}$ Using MTR histograms, the peak height, but not position, was found to be lower in subjects with AD than controls. ${ }^{199,202,203}$ All of the observed reductions in MTR could potentially arise from reductions in myelin. Table 3 summarizes myelin-related MR changes observed in AD.

\section{Wallerian degeneration}

When an axon is transected, the remaining portion of the axon will degenerate back to the cell body. The myelin was believed to be immediately removed, but more recent experiments by Trapp et al. ${ }^{204}$ have shown that myelin debris can remain for several months before being taken away by macrophages. This myelin debris, although not in the form of intact myelin, may still contribute to the MWF signal. ${ }^{61}$ Eventually, the myelin is removed and changes in MR parameters consistent with demyelination can be measured. Wallerian degeneration can be found in ischemia due to stroke, ${ }^{205-207}$ WM changes in AD, ${ }^{193,208,209}$ amyotrophic lateral sclerosis, ${ }^{210}$ diffuse damage measured in MS NAWM, ${ }^{184-186}$ spinal cord ${ }^{211,212}$ injury, and many other neurodegenerative diseases affecting the integrity of axons. As an interesting note, after spinal cord injury, regeneration of the axons has been shown to be inhibited by the presence of myelin, ${ }^{213,214}$ highlighting the deep association between axons and myelin.

\section{DYSMYELINATION}

Whereas demyelination is the destruction or loss of previously healthy myelin, dysmyelination is the defective formation of myelin during development, often involving biochemical abnormalities. Because a reduction of myelin is the outcome of both conditions, no MR technique related to myelination can differentiate between demyelination and dysmyelination. A wide range of dysmyelinating disorders exists, also nicely presented by Filley. ${ }^{144}$

\section{Leukodystrophies}

In childhood, congenital defects (usually metabolic in origin), which interfere with the normal development of myelin fall within the category of leukodystrophies. Pattern recognition on conventional $T_{1}$-weighted and $T_{2}$ weighted images can be quite useful in diagnosing some of these metabolic disorders, ${ }^{215}$ and in recent years, newer MR techniques such as MTR and diffusion have also been used to learn more about leukodystrophies. The MTR of WM in leukodystrophy patients was found to be lower than that of controls. ${ }^{198,216}$ The $\langle D\rangle$ was found to be either decreased (e.g., with inflammatory changes seen in adrenoleukodystrophy) or increased (e.g., with 
abnormal myelin formation in metachromatic leukodystrophy), depending on the origin of the disorder, but anisotropy tended to decrease in all cases. ${ }^{18,217-219} \mathrm{Ob}$ served increases in $\langle D\rangle$ in some dysmyelinating disorders may be understood by examining animal models of dysmyelination, which have found increases in $\lambda_{\perp},{ }^{23,95}$ and either increases ${ }^{95}$ or no change ${ }^{23}$ in $\lambda_{\|}$, relative to controls. Spectroscopy has also shown changes in the spectrum of affected individuals with increases in choline and myoinositol in both Krabbe and Alexander disease $^{220-223}$ attributed to loss of myelin. Magnetic resonance spectroscopy of dysmyelination disorders such as metachromatic leukodystrophy ${ }^{224}$ and Canavan's disease ${ }^{225,226}$ have shown decreases in the choline peak. All these changes have been attributed to the lower myelin content of dysmyelinated WM. Magnetic resonance spectroscopy of Zellweger syndrome has shown the presence of a lipid peak, ${ }^{227,228}$ whereas other leukodystrophies do not tend to exhibit any lipid signal. ${ }^{228}$ Groenendaal et al. ${ }^{227}$ hypothesize the lipid observed in Zellweger could potentially arise from the breakdown of myelin, but may also be due to abnormal storage of neutral fat in astrocytes and phagocytes. Table 3 summarizes myelin-related MR changes observed in leukodystrophies.

\section{Phenylketonuria}

Phenylketonuria (PKU) is an inborn error of phenylalanine metabolism that causes severe mental retardation in most affected individuals who are not treated with a diet restricted in PHE. A number of studies have observed myelin abnormalities in the brain and spinal cord of subjects with PKU. ${ }^{229-232}$ Early work by Shah et al. ${ }^{233}$ comparing the lipid composition of cerebral WM and myelin in subjects with PKU to controls found the total lipid content to be lower and the ratio of cholesterol to galactolipid to be higher in subjects with PKU. Furthermore, the amount of myelin recovered from the brains of PKU patients was on average $40 \%$ lower than from controls. The authors suggest that the observed deficiency of myelin may reflect an early arrest of myelination. A very recent study by Sirrs et al. ${ }^{234}$ found the MWF to be reduced by up to $56 \%$ in normal-appearing WM of subjects with PKU; a reduction in MWF was also observed in diffuse WM lesions. Choline has been observed to be decreased in PKU lesions in some, ${ }^{235,236}$ but not all studies. ${ }^{237}$ Like the inflammatory type of leukodystrophies, diffusion studies found decreased FA and $\langle D\rangle$ in $\mathrm{WM},{ }^{238,239}$ and reduced $\langle D\rangle$ in diffusion-weighted imaging hyperintense areas in PKU. ${ }^{235,240}$ Table 3 summarizes myelin-related MR changes observed in PKU.

\section{Schizophrenia}

Myelination in the frontal brain regions continues well into the second decade of life. Schizophrenia often develops during this late period of brain maturation and is characterized by disorganized thinking, delusions, hallu- cinations, changes in emotions, and changes in behavior. Despite effective treatments for psychotic symptoms, the mechanisms that account for disability are poorly understood. There is growing evidence for neuronal and oligodendrocyte-related abnormalities being associated with schizophrenia. Hakak et al. ${ }^{241}$ found an abnormal expression of myelin-related genes in schizophrenia and using electron microscopy, Uranova et al. ${ }^{242}$ observed damage to the myelin sheath due to the formation of concentric lamellar bodies and decreased volume density of mitochondria in oligodendrocytes in the postmortem brain. ${ }^{242}$ Tkachev et al. ${ }^{243}$ also observed myelin and fatty-acid biosynthesis dysfunction in schizophrenia based on postmortem brain studies. Magnetic resonance imaging of schizophrenia has also provided evidence of myelin abnormalities within the WM. Flynn et al. ${ }^{131}$ found a mean $12 \%$ decrease in MWF in the WM of schizophrenia subjects when compared to controls. Furthermore, in healthy subjects, MWF of frontal WM and total WM increased with age and years of education, whereas this relationship was not observed in schizophrenia. Bartzokis et al. ${ }^{244}$ also demonstrated a relationship between WM and GM ratio and age in controls, which was not observed in subjects with schizophrenia. These findings suggest that the normal WM development and myelination is dysregulated in schizophrenia. ${ }^{245}$ Some studies have found elevated phosphodiesters in schizophrenia, implying increased membrane breakdown products, ${ }^{246,247}$ although choline has been reported as normal in several studies. ${ }^{248,249}$ Studies in diffusion have also observed WM abnormalities, such as decreases in fractional anisotropy ${ }^{250-252}$ and increases in $\langle D\rangle .^{253,254}$ Kitamura et al. ${ }^{255}$ observed decreased FA in schizophrenia WM, but found this reduction could be accounted for by the observed increase in $\lambda_{\perp}$. Using a 2-echo fast-spinecho experiment, Pfefferbaum et al. ${ }^{256}$ showed subjects with schizophrenia had significantly longer $\mathrm{WM} \mathrm{T}_{2}$. A number of studies have observed decreased MTR in schizophrenia WM. ${ }^{252,257,258}$ All these findings are consistent with a decrease in the myelination state for schizophrenia WM. Table 3 summarizes myelin-related MR changes observed in schizophrenia.

\section{REMYELINATION}

The brain has a limited capacity to repair itself after damage. Myelinating oligodendrocytes may be recruited in areas of damage and reform myelin, although the internode distance is shorter and the myelin thickness is decreased compared with normal myelin. ${ }^{259}$ With myelin staining, areas of remyelination may show a pallor and are referred to as "shadow plaques." ${ }^{260}$ The ability to measure remyelination in vivo would be extremely useful in monitoring drug therapies as well as giving new insight into progression of disease. 
Conventional MR can not differentiate remyelination from other pathologies; however, newer techniques show more promise. A number of studies investigating remyelination in animal models have been completed. From an animal model of demyelination, a predicted remyelination at 6 weeks after cuprizone treatment was detected using the texture analysis parameter, horizontal gray level nonuniformity, on $\mathrm{T}_{2}$-weighted images. ${ }^{261} \mathrm{In}$ several other studies involving cuprizone diet in mice, measurement of $\lambda_{\perp}$ was found to increase with demyelination and subsequently decrease with remyelination. However, $\lambda_{\perp}$ did not return to pretreatment values. ${ }^{90,92}$ In another study, again examining a cuprizone mouse model, Merkler et al. ${ }^{262}$ were able to classify regions with $95 \%$ accuracy into normal, demyelinated, or remyelinated WM using discriminate function analysis of $\mathrm{T}_{1}, \mathrm{~T}_{2}$, and MTR. In a study of injured rat sciatic nerve, Webb et al. ${ }^{61}$ demonstrated that MWF reflected myelin loss and remyelination due to Wallerian degeneration and regeneration. Deloire-Grassin et al. ${ }^{65}$ induced demyelinating lesions in rats and examined MTR at varying stages of demyelination and remyelination in comparison to histology. The profile of MTR correlated well with the course of demyelination and remyelination. Schwann cells and olfactory ensheathing cells have been shown to promote remyelination after transplantation. ${ }^{263}$ These cells can be labeled with a superparamagnetic iron oxide that allows them to be visualized with MR. Recently, these transplanted cells were shown to promote remyelination in rat spinal cord and could be followed with $\mathrm{T}_{2}$-weighted imaging. ${ }^{264}$

Some work studying remyelination in humans has also been completed. In biopsy and postmortem studies of the MS brain, lesion hypointensity on $\mathrm{T}_{1}$-weighted images increased with increasing demyelination, and subsequently decreased with remyelination, with some lesions returning to isointensity compared to the surrounding WM. ${ }^{85,86,159,265}$ In two MRS studies, MS lesions showed a decrease in choline and lipid signals, which could be attributed to remyelination, but also to a decrease in edema and inflammation. ${ }^{169,266}$ In a serial MS study, several large lesions showed dramatic decreases in MWF at first appearance, presumably due to demyelination. A subset of these lesions then exhibited a subsequent increase in MWF, indicating possible remyelination. ${ }^{267}$ Comparing postmortem MTR to histopathology in the MS brain, Barkhof et al. ${ }^{159}$ found that although remyelinated lesions showed a higher MTR than demyelinated lesions, they were still below NAWM values. Measuring the inhomogeneity of MTR in lesions was used to determine whether regions would show subsequent increases or decreases in MTR. Voxels with a low MTR in regions of high MTR inhomogeneity showed increases in MTR after 2 months. These MTR increases were attributed to remyelination. $^{268}$ Table 3 summarizes myelin-related MR changes observed in remyelination.

\section{CONCLUSIONS}

In this review we have reported on the extensive literature that uses MR to image myelin. We close with a brief critical assessment of the relative merits of the different MR approaches used.

\section{MR techniques for monitoring myelin}

It is clear that myelination affects the values of most MR parameters. Hence, we find a very large number of different approaches to monitoring myelination in the literature. In this review we reported seven approaches, but we focused on the five most common techniques. We provide a critical summary on each of these techniques below:

Conventional $\mathrm{T}_{1}$-weighted and $\mathrm{T}_{2}$-weighted imaging approaches have seen the largest application in the study of children under the age of 2 years, because by far the greatest changes in relaxation time weighting occur in this age range. Two cautions come to mind with this approach: 1) given that $T_{1}$ and $T_{2}$ are heavily influenced by $\mathrm{WC}$, the observed changes in brain development are not necessarily specific to myelination; and 2) there is a large amount of literature on the influence of iron on $\mathrm{T}_{1}$ and $T_{2}$ in the brain (reviewed elsewhere in this volume by Stankiewicz et al. ${ }^{269}$ ). Consequently, for older subjects, the use of conventional relaxation time weighting as a myelin measure is not appropriate. For this reason, we caution researchers to reserve this qualitative approach to subjects under the age of 2 years.

With MRS, the presence of neutral lipid, assuming it can be isolated from lactate, is most likely a result of active demyelination. However, proton MRS is not capable of assessing the content of intact myelin, and currently, it has a limited resolution.

The research community is largely in agreement about the relationship between DTI parameters and myelin, due to a series of elegant studies on animal models of human disease. To summarize, measurements of changes in radial diffusivity, $\lambda_{\perp}$, give information on changes in myelination, but the absolute value of $\lambda_{\perp}$ also depends on the degree of fiber tract orientational order within the imaging voxel. Also, small changes in $\lambda_{\perp}$ may only be detectable in regions of high anisotropy and not in areas of low anisotropy, such as regions of crossing fibers or gray/WM interfaces. ${ }^{174}$

It is well established that MTR is a robust and very sensitive indicator of tissue integrity; hence this parameter has great value for monitoring CNS pathology. However, there continues to be controversy about the relationship between MTR and myelin. Models for magnetization transfer in CNS tissue (e.g., Stanisz et al., ${ }^{34}$ 1999) suggest that MTR is influenced by changes in WC 
and $\mathrm{T}_{1}$, as well as changes in myelin. Also the MTR value includes magnetization transfer and direct saturation effects, both of which depend critically on the pulse sequence parameters. ${ }^{34,270}$ The degree of direct saturation can differ between tissues and water compartments in a manner that again depends on the nature of the pulse sequence. ${ }^{32}$ Most magnetization transfer models assume a two-pool system (i.e., water and nonaqueous tissue), although WM is known to be more complicated. The magnetization transfer effect depends not only on the presence of two (or more) proton pools, but also on the exchange rate between the pools, which itself may vary with $\mathrm{pH}$, temperature, and pathology. ${ }^{71}$ The ratio of GMmeasured to WM-measured values of MTR and $\mathrm{F}^{25}$ are typically $50 \%$ or higher, whereas histological measures of myelination in CNS tissue indicate that GM has on average about $10 \%$ to $20 \%$ as much myelin as WM (Tables 1 and 2). The current understanding of magnetization transfer contrast in CNS tissue is an area of active research; improved modeling for this may result in a robust technique for measuring myelination. However, although there is a great deal of evidence to indicate that myelination plays a role in determining the MTR value, it is inappropriate to associate changes in MTR solely with changes in myelin content.

In the opinion of the authors of this review, the short $\mathrm{T}_{2}$ component from water in myelin provides the most specific measure of CNS myelination available today. This is best demonstrated from the perusal of Tables 1 and 2, which show plots of MWF versus a histological measure of myelination. The plots from Webb et al., ${ }^{61} 2003$ (PNS) and Laule et al., ${ }^{78} 2006$ (CNS) show linear relations (with near zero intercept) across the entire range of data acquired, and for the CNS data, GM, lesions and WM points fit the same line. When compared to the other plots in Tables 1 and 2, these show the most promise for a robust linear relationship between MR myelin marker and myelin content. A key point here is that plots of measured relationships are more informative than $R^{2}$ values.

\section{Concluding remark}

In conclusion, we continue to learn a great deal about myelin from MR studies. Many researchers have played a key role in understanding myelin development in neonates and young children, as well as in the maturing adult. Most neurodegenerative diseases have a myelination component that can be elucidated by MR. We believe that in the future there will be a greater understanding in the research community regarding the optimal MR approach or approaches for imaging myelin with continued research, advancements in high-field imaging, and further discussion.

Acknowledgments: We thank the MS Society of Canada for their continued grant support. We also wish to thank Eugene
Yip for his assistance and Campbell Clark for his helpful comments.

\section{REFERENCES}

1. Morell P, Quarles RH, Norton W. Formation, structure, and biochemistry of myelin. In: Siegel J, ed. Basic Neurochemistry: Molecular, Cellular, and Medical Aspects, 4th ed. New York: Raven Press Ltd., 1989:109-136.

2. Van De Graff KM. Nervous tissue and the central nervous system. In: Van De Graff KM. Human Anatomy, 6th ed. New York: McGraw-Hill, 2002:351.

3. Trapp B, Kidd G. Structure of the myelinated axon. In: Lazzarini R, ed. Myelin Biology and Disorders 1. London: Elsevier Academic Press, 2004:3-27.

4. Taylor C, Marta C, Bansal R, Pfeiffer S. The transport, assembly, and function of myelin lipids. In: Lazzarini R, ed. Myelin Biology and Disorders 1. London: Elsevier Academic Press, 2004:57-88.

5. Kirschner DA, Ganser AL, Caspar DLD. Diffraction studies of molecular organization and membrane interactions in myelin. In: Morell P, ed. Myelin, 2nd ed. New York: Plenum Press, 1984: 51-95.

6. Edgar JM, McLaughlin M, Yool D, et al. Oligodendroglial modulation of fast axonal transport in a mouse model of hereditary spastic paraplegia. J Cell Biol 2004;166:121-131.

7. Bjartmar C, Trapp BD. Axonal and neuronal degeneration in multiple sclerosis: mechanisms and functional consequences. Curr Opin Neurol 2001;14:271-278.

8. Kirkpatrick LL, Witt AS, Payne HR, et al. Changes in microtubule stability and density in myelin-deficient shiverer mouse CNS axons. J Neurosci 2001;21:2288-2297.

9. Edgar JM, Garbern J. The myelinated axon is dependent on the myelinating cell for support and maintenance: molecules involved. J Neurosci Res 2004;76:593-598.

10. Boucher SE, Cypher MA, Carlock LR, Skoff RP. Proteolipid protein gene modulates viability and phenotype of neurons. J Neurosci 2002;22:1772-1783.

11. Dyer CA. The structure and function of myelin: from inert membrane to perfusion pump. Neurochem Res 2002;27:1279-1292.

12. Tsunoda I, Fujinami RS. Inside-out versus outside-in models for virus induced demyelination: axonal damage triggering demyelination. Springer Semin Immunopathol 2002;24:105-125.

13. Mottershead JP, Schmierer K, Clemence M, et al. High field MRI correlates of myelin content and axonal density in multiple sclerosis - a post-mortem study of the spinal cord. J Neurol 2003; 250:1293-1301.

14. Schmierer K, Scaravilli F, Altmann DR, et al. Magnetization transfer ratio and myelin in postmortem multiple sclerosis brain. Ann Neurol 2004;56:407-415.

15. Stewart WA, MacKay AL, Whittall KP, et al. Spin-spin relaxation in experimental allergic encephalomyelitis. Analysis of CPMG data using a non-linear least squares method and linear inverse theory. Magn Reson Med 1993;29:767-775.

16. Waldman A, Rees JH, Brock CS, et al. MRI of the brain with ultra-short echo-time pulse sequences. Neuroradiology 2003;45: 887-892.

17. Kilby PM, Bolas NM, Radda GK. 31P-NMR study of brain phospholipid structures in vivo. Biochim Biophys Acta 1991; 1085:257-264.

18. Barkovich AJ. Magnetic resonance techniques in the assessment of myelin and myelination. J Inherit Metab Dis 2005;28:311-343.

19. Fatouros PP, Marmarou A. Use of magnetic resonance imaging for in vivo measurements of water content in human brain: method and normal values. J Neurosurg 1999;90:109-115.

20. Kamman RL, Go KG, Brouwer W, Berendsen HJ. Nuclear magnetic resonance relaxation in experimental brain edema: effects of water concentration, protein concentration, and temperature. Magn Reson Med 1988;6:265-274.

21. Beaulieu C. The basis of anisotropic water diffusion in the nervous system - a technical review. NMR Biomed 2002;15:435455. 
22. Song SK, Sun SW, Ju WK, et al. Diffusion tensor imaging detects and differentiates axon and myelin degeneration in mouse optic nerve after retinal ischemia. Neuroimage 2003;20:1714-1722.

23. Song SK, Sun SW, Ramsbottom MJ, et al. Dysmyelination revealed through MRI as increased radial (but unchanged axial) diffusion of water. Neuroimage 2002;17:1429-1436.

24. Wolff SD, Balaban RS. Magnetization transfer contrast (MTC) and tissue water proton relaxation in vivo. Magn Reson Med 1989;10:135-144.

25. Sled JG, Levesque I, Santos AC, et al. Regional variations in normal brain shown by quantitative magnetization transfer imaging. Magn Reson Med 2004;51:299-303.

26. Ropele S, Strasser-Fuchs S, Augustin M, et al. A comparison of magnetization transfer ratio, magnetization transfer rate, and the native relaxation time of water protons related to relapsing-remitting multiple sclerosis. AJNR Am J Neuroradiol 2000;21:18851891.

27. Ropele S, Seifert T, Enzinger C, Fazekas F. Method for quantitative imaging of the macromolecular $1 \mathrm{H}$ fraction in tissues. Magn Reson Med 2003;49:864-871.

28. Gareau PJ, Rutt BK, Karlik SJ, Mitchell JR. Magnetization transfer and multicomponent T2 relaxation measurements with histopathologic correlation in an experimental model of MS. J Magn Reson Imaging 2000;11:586-595.

29. MacKay A, Whittall K, Adler J, et al. In vivo visualization of myelin water in brain by magnetic resonance. Magn Reson Med 1994;31:673-677.

30. Whittall KP, MacKay AL, Graeb DA, et al. In vivo measurement of T2 distributions and water contents in normal human brain. Magn Reson Med 1997;37:34-43.

31. Poon CS, Henkelman RM. Practical T2 quantitation for clinical applications. J Magn Reson Imaging 1992;2:541-553.

32. Vavasour IM, Whittall KP, Li DK, MacKay AL. Different magnetization transfer effects exhibited by the short and long $\mathrm{T}(2)$ components in human brain. Magn Reson Med 2000;44:860 866.

33. Bjarnason T, Vavasour I, Chia C, MacKay A. Characterization of the NMR behaviour of white matter in bovine brain. Magn Reson Med 2005;54:1072-1081.

34. Stanisz GJ, Kecojevic A, Bronskill MJ, Henkelman RM. Characterizing white matter with magnetization transfer and $\mathrm{T}(2)$. Magn Reson Med 1999;42:1128-1136.

35. Oh J, Han ET, Pelletier D, Nelson SJ. Measurement of in vivo multi-component $\mathrm{T} 2$ relaxation times for brain tissue using multislice T2 prep at 1.5 and 3 T. Magn Reson Imaging 2006;24:3343.

36. Foltz WD, Al-Kwifi O, Sussman MS, et al. Optimized spiral imaging for measurement of myocardial T2 relaxation. Magn Reson Med 2003;49:1089-1097.

37. Mädler B, MacKay AL. In-vivo 3D multi-component T2-relaxation measurements for quantitative myelin imaging at 3T. 14th Annual Meeting of the International Society of Magnetic Resonance in Medicine, Seattle, 2006:2112.

38. Fenrich FR, Beaulieu C, Allen PS. Relaxation times and microstructures. NMR Biomed 2001;14:133-139.

39. Graham SJ, Stanchev PL, Bronskill MJ. Criteria for analysis of multicomponent tissue T2 relaxation data. Magn Reson Med 1996;35:370-378.

40. Whittall KP, MacKay AL. Quantitative interpretation of NMR relaxation data. J Magn Reson 1989;84:64-71.

41. Lawson CL, Hanson RJ. Solving least squares problems. Englewood Cliffs, NJ: Prentice-Hall, 1974:1-311.

42. Stanisz GJ, Henkelman RM. Diffusional anisotropy of T2 components in bovine optic nerve. Magn Reson Med 1998;40:405410.

43. Jones CK, Xiang QS, Whittall KP, MacKay AL. Linear combination of multiecho data: short T2 component selection. Magn Reson Med 2004;51:495-502.

44. Vidarsson L, Conolly SM, Lim KO, et al. Echo time optimization for linear combination myelin imaging. Magn Reson Med 2005; $53: 398-407$.
45. Does MD, Beaulieu C, Allen PS, Snyder RE. Multi-component T1 relaxation and magnetization transfer in peripheral nerve. Magn Reson Imaging 1998;16:1033-1041.

46. Tozer DJ, Davies GR, Altmann DR, et al. Correlation of apparent myelin measures obtained in multiple sclerosis patients and controls from magnetization transfer and multicompartmental T2 analysis. Magn Reson Med 2005;53:1415-1422.

47. Wu Y, Alexander AL, Fleming JO, et al. Myelin water fraction in human cervical spinal cord in vivo. J Comput Assist Tomogr 2006;30:304-306.

48. Chia CLL, Bjarnason TA, Mackay AL, Pike GB. Cross-site reproducibility of myelin water estimates. 14th Annual Meeting of the International Society of Magnetic Resonance in Medicine, Seattle, 2006:2520.

49. Oakden W, Lobaugh NJ, Black SE, Stanisz GJ. T2 hyperintensity does not always mean demyelination (and neither does decreased fractional anisotropy). Proceedings from Imaging myelin: formation, destruction and repair. Vancouver, Canada, 2006:P41.

50. Dula AN, Does MD, Gochberg DF. Proceedings from Imaging of myelin in ferret brain using magnetic resonance multi-component T2 and qMT. Imaging myelin: formation, destruction and repair. Vancouver, BC, 2006:P39.

51. Du YP, Chu R, Brown MS, et al. Quantitative multi-slice mapping of the myelin water fraction using multi-compartment analysis of T2* relaxation at 3T. 14th Annual Meeting of the International Society of Magnetic Resonance in Medicine, Seattle, 2006:2104.

52. Swift TJ, Fritz OG Jr. A proton spin-echo study of the state of water in frog nerves. Biophys J 1969;9:54-59.

53. Vasilescu V, Katona E, Simplaceanu V, Demco D. Water compartments in the myelinated nerve. III. Pulsed NMR results. Experientia 1978;34:1443-1444.

54. Does MD, Snyder RE. T2 relaxation of peripheral nerve measured in vivo. Magn Reson Imaging 1995;13:575-580.

55. Menon RS, Rusinko MS, Allen PS. Proton relaxation studies of water compartmentalization in a model neurological system. Magn Reson Med 1992;28:264-274.

56. Jolesz FA, Polak JF, Adams DF, Ruenzel PW. Myelinated and nonmyelinated nerves: comparison of proton MR properties. Radiology 1987;164:89-91.

57. Kucharczyk W, Macdonald PM, Stanisz GJ, Henkelman RM Relaxivity and magnetization transfer of white matter lipids at MRI: importance of cerebrosides and pH. Radiology 1994;192: 521-529.

58. Jolesz FA, Polak JF, Ruenzel PW, Adams DF. Wallerian degeneration demonstrated by magnetic resonance: spectroscopic measurements on peripheral nerve. Radiology 1984;152:85-87.

59. Titelbaum DS, Frazier JL, Grossman RI, et al. Wallerian degeneration and inflammation in rat peripheral nerve detected by in vivo MRI. AJNR Am J Neuroradiol 1989;10:741-746.

60. Does MD, Snyder RE. Multiexponential T2 relaxation in degenerating peripheral nerve. Magn Reson Med 1996;35:207-213.

61. Webb S, Munro CA, Midha R, Stanisz GJ. Is multicomponent T2 a good measure of myelin content in peripheral nerve? Magn Reson Med 2003;49:638-645.

62. Wessig C, Bendszus M, Stoll G. In vivo visualization of focal demyelination in peripheral nerves by gadofluorine $\mathrm{M}$-enhanced magnetic resonance imaging. Exp Neurol 2006;15:15.

63. Dousset V, Brochet B, Vital A, et al. Lysolecithin-induced demyelination in primates: preliminary in vivo study with MR and magnetization transfer. AJNR Am J Neuroradiol 1995;16:225231.

64. Dousset V, Grossman RI, Ramer KN, et al. Experimental allergic encephalomyelitis and multiple sclerosis: lesion characterization with magnetization transfer imaging [erratum appears in Radiology 1992;183:878]. Radiology 1992;182:483-491.

65. Deloire-Grassin MS, Brochet B, Quesson B, et al. In vivo evaluation of remyelination in rat brain by magnetization transfer imaging. J Neurol Sci 2000;178:10-16.

66. McGowan JC, Berman JI, Ford JC, et al. Characterization of experimental spinal cord injury with magnetization transfer ratio histograms. J Magn Reson Imaging 2000;12:247-254. 
67. Brochet B, Dousset V. Pathological correlates of magnetization transfer imaging abnormalities in animal models and humans with multiple sclerosis. Neurology 1999;53:S12-17.

68. Cook LL, Foster PJ, Mitchell JR, Karlik SJ. In vivo 4.0-T magnetic resonance investigation of spinal cord inflammation, demyelination, and axonal damage in chronic-progressive experimental allergic encephalomyelitis. J Magn Reson Imaging 2004;20:563571.

69. Blezer EL, Bauer J, Brok HP, et al. Quantitative MRI-pathology correlations of brain white matter lesions developing in a nonhuman primate model of multiple sclerosis. NMR Biomed 2007; 20:90-103.

70. Gareau PJ, Rutt BK, Bowen CV, et al. In vivo measurements of multi-component T2 relaxation behaviour in guinea pig brain. Magn Reson Imaging 1999;17:1319-1325.

71. Stanisz GJ, Webb S, Munro CA, et al. MR properties of excised neural tissue following experimentally induced neuroinflammation. Magn Reson Med 2004;51:473-479.

72. Yung A, Choo A, Liu J, et al. Measurements of myelin water in rat spinal cord in vivo [abstract]. Int Soc Magn Reson Med, Kyoto, Japan, 2004:1537.

73. Pun TW, Odrobina E, Xu QG, et al. Histological and magnetic resonance analysis of sciatic nerves in the tellurium model of neuropathy. J Peripher Nerv Syst 2005;10:38-46.

74. Odrobina EE, Lam TY, Pun T, et al. MR properties of excised neural tissue following experimentally induced demyelination. NMR Biomed 2005;18:277-284.

75. van Waesberghe JH, Kamphorst W, De Groot CJ, et al. Axonal loss in multiple sclerosis lesions: magnetic resonance imaging insights into substrates of disability. Ann Neurol 1999;46:747754.

76. Bot JC, Blezer EL, Kamphorst W, et al. The spinal cord in multiple sclerosis: relationship of high-spatial-resolution quantitative MRI findings to histopathologic results. Radiology 2004; 233:531-540.

77. Nagara H, Inoue T, Koga T, et al. Formalin fixed brains are useful for magnetic resonance imaging (MRI) study. J Neurol Sci 1987; 81:67-77.

78. Laule C, Leung E, Li DK, et al. Myelin water imaging in multiple sclerosis: quantitative correlations with histopathology. Mult Scler 2006;12:747-753.

79. Moore GRW, Leung E, MacKay AL, et al. A pathology-MRI study of the short-T2 component in formalin-fixed multiple sclerosis brain. Neurology 2000;55:1506-1510.

80. Klüver H, Barrera E. A method for the combined staining of cells and fibres in the nervous system. J Neuropathol Exp Neurol 1953;12:400-403.

81. Segarra J. Histological and Histochemical Staining Methods. In: Teduchi C, ed. Neuropathology Methods and Diagnosis. Boston: Little, Brown and Company, 1970:233-269.

82. Salthouse T. Luxol fast blue ARN: a new solvent azo dye with improved staining qualities for myelin and phospholipids. Stain Technol 1962;37:313-316.

83. Lycette R, Danforth J, Koppel J, Olwin J. The binding of luxol fast blur ARN by various biological lipids. Stain Technol 1970; 45:155-160.

84. Teresi LM, Hovda D, Seeley AB, et al. MR imaging of experimental demyelination. AJR Am J Roentgenol 1989;152:12911298.

85. van Walderveen MA, Kamphorst W, Scheltens P, et al. Histopathologic correlate of hypointense lesions on T1-weighted spin-echo MRI in multiple sclerosis. Neurology 1998;50:12821288.

86. Bitsch A, Kuhlmann T, Stadelmann C, et al. A longitudinal MRI study of histopathologically defined hypointense multiple sclerosis lesions. Ann Neurol 2001;49:793-796.

87. Bergers E, Bot JC, De Groot CJ, et al. Axonal damage in the spinal cord of MS patients occurs largely independent of T2 MRI lesions. Neurology 2002;59:1766-1771.

88. Lycklama a Nijeholt GJ, Uitdehaag BM, Bergers E, et al. Spinal cord magnetic resonance imaging in suspected multiple sclerosis. Eur Radiol 2000;10:368-376.
89. Bo L, Geurts JJ, van der Valk P, et al. Lack of correlation between cortical demyelination and white matter pathologic changes in multiple sclerosis. Arch Neurol 2007;64:76-80.

90. Song SK, Yoshino J, Le TQ, et al. Demyelination increases radial diffusivity in corpus callosum of mouse brain. Neuroimage 2005; 26:132-140.

91. Sun SW, Liang HF, Le TQ, et al. Differential sensitivity of in vivo and ex vivo diffusion tensor imaging to evolving optic nerve injury in mice with retinal ischemia. Neuroimage 2006;32:11951204.

92. Sun SW, Liang HF, Trinkaus K, et al. Noninvasive detection of cuprizone induced axonal damage and demyelination in the mouse corpus callosum. Magn Reson Med 2006;55:302-308.

93. Sun SW, Neil JJ, Song SK. Relative indices of water diffusion anisotropy are equivalent in live and formalin-fixed mouse brains. Magn Reson Med 2003;50:743-748.

94. Sun SW, Song SK, Harms MP, et al. Detection of age-dependent brain injury in a mouse model of brain amyloidosis associated with Alzheimer's disease using magnetic resonance diffusion tensor imaging. Exp Neurol 2005;191:77-85.

95. Biton IE, Duncan ID, Cohen Y. High b-value q-space diffusion MRI in myelin-deficient rat spinal cords. Magn Reson Imaging 2006;24:161-166

96. Ford JC, Hackney DB, Alsop DC, et al. MRI characterization of diffusion coefficients in a rat spinal cord injury model. Magn Reson Med 1994;31:488-494.

97. Kim JH, Budde MD, Liang HF, et al. Detecting axon damage in spinal cord from a mouse model of multiple sclerosis. Neurobiol Dis 2006;21:626-632.

98. Harsan LA, Poulet P, Guignard B, et al. Brain dysmyelination and recovery assessment by noninvasive in vivo diffusion tensor magnetic resonance imaging. J Neurosci Res 2006;83:392-402.

99. Schmierer K, Wheeler-Kingshott CA, Boulby PA, et al. Diffusion tensor imaging of post mortem multiple sclerosis brain. Neuroimage 2007;35:467-477.

100. Yakovlev P, Lecours A. The myelogenic cycles of regional maturation of the brain. In: Minkowski A, ed. Regional Development of the Brain in Early Life. Oxford: Blackwell, 1967:3-70.

101. Valencia MP, Castillo M. MRI findings in posttraumatic spinal cord Wallerian degeneration. Clin Imaging 2006;30:431-433

102. Kinney HC, Brody BA, Kloman AS, Gilles FH. Sequence of central nervous system myelination in human infancy. II. Patterns of myelination in autopsied infants. J Neuropathol Exp Neurol 1988;47:217-234

103. Matsumae M, Kurita D, Atsumi H, et al. Sequential changes in MR water proton relaxation time detect the process of rat brain myelination during maturation. Mech Ageing Dev 2001;122: 1281-1291.

104. Barkovich AJ, Kjos BO, Jackson DE Jr., Norman D. Normal maturation of the neonatal and infant brain: MR imaging at $1.5 \mathrm{~T}$. Radiology 1988;166:173-180.

105. Huppi PS, Maier SE, Peled S, et al. Microstructural development of human newborn cerebral white matter assessed in vivo by diffusion tensor magnetic resonance imaging. Pediatr Res 1998; 44:584-590.

106. Morriss MC, Zimmerman RA, Bilaniuk LT, et al. Changes in brain water diffusion during childhood. Neuroradiology 1999;41: 929-934.

107. Klingberg T, Vaidya CJ, Gabrieli JD, et al. Myelination and organization of the frontal white matter in children: a diffusion tensor MRI study. Neuroreport 1999;10:2817-2821.

108. van der Knaap MS, Valk J. Magnetic resonance of myelin, myelination and myelin disorders. New York: Springer, 1996:31-38.

109. Prayer D, Barkovich AJ, Kirschner DA, et al. Visualization of nonstructural changes in early white matter development on diffusion-weighted MR images: evidence supporting premyelination anisotropy. AJNR Am J Neuroradiol 2001;22:1572-1576.

110. Ashtari M, Cervellione KL, Hasan KM, et al. White matter development during late adolescence in healthy males: A crosssectional diffusion tensor imaging study. Neuroimage 2007;26: 26.

111. Sullivan EV, Pfefferbaum A. Diffusion tensor imaging and aging. Neurosci Biobehav Rev 2006;30:749-761. 
112. Ota M, Obata T, Akine Y, et al. Age-related degeneration of corpus callosum measured with diffusion tensor imaging. Neuroimage 2006;31:1445-1452.

113. Pfefferbaum A, Sullivan EV, Hedehus M, et al. Age-related decline in brain white matter anisotropy measured with spatially corrected echo-planar diffusion tensor imaging. Magn Reson Med 2000;44:259-268.

114. Salat DH, Tuch DS, Hevelone ND, et al. Age-related changes in prefrontal white matter measured by diffusion tensor imaging. Ann N Y Acad Sci 2005;1064:37-49.

115. van Buchem MA, Steens SC, Vrooman HA, et al. Global estimation of myelination in the developing brain on the basis of magnetization transfer imaging: a preliminary study. AJNR Am J Neuroradiol 2001;22:762-766.

116. Engelbrecht V, Rassek M, Preiss S, et al. Age-dependent changes in magnetization transfer contrast of white matter in the pediatric brain. AJNR Am J Neuroradiol 1998;19:1923-1929.

117. Silver NC, Barker GJ, MacManus DG, et al. Magnetisation transfer ratio of normal brain white matter: a normative database spanning four decades of life. J Neurol Neurosurg Psychiatry 1997;62:223-228.

118. Armstrong CL, Traipe E, Hunter JV, et al. Age-related, regional, hemispheric, and medial-lateral differences in myelin integrity in vivo in the normal adult brain. AJNR Am J Neuroradiol 2004; 25:977-984.

119. Rovaris M, Iannucci G, Cercignani M, et al. Age-related changes in conventional, magnetization transfer, and diffusion-tensor MR imaging findings: study with whole-brain tissue histogram analysis. Radiology 2003;227:731-738.

120. Mehta RC, Pike GB, Enzmann DR. Magnetization transfer MR of the normal adult brain. AJNR Am J Neuroradiol 1995;16:20852091.

121. Vavasour IM, Clark CM, Li DK, Mackay AL. Reproducibility and reliability of MR measurements in white matter: clinical implications. Neuroimage 2006;32:637-642.

122. Vavasour IM, Whittall KP, MacKay AL, et al. A comparison between magnetization transfer ratios and myelin water percentages in normals and multiple sclerosis patients. Magn Reson Med 1998;40:763-768.

123. Cady EB, Penrice J, Amess PN, et al. Lactate, N-acetylaspartate, choline and creatine concentrations, and spin-spin relaxation in thalamic and occipito-parietal regions of developing human brain. Magn Reson Med 1996;36:878-886.

124. Kreis R, Ernst T, Ross BD. Development of the human brain: in vivo quantification of metabolite and water content with proton magnetic resonance spectroscopy. Magn Reson Med 1993;30: 424-437.

125. Barker PB, Soher BJ, Blackband SJ, et al. Quantitation of proton NMR spectra of the human brain using tissue water as an internal concentration reference. NMR Biomed 1993;6:89-94.

126. Brooks JC, Roberts N, Kemp GJ, et al. A proton magnetic resonance spectroscopy study of age-related changes in frontal lobe metabolite concentrations. Cereb Cortex 2001;11:598-605.

127. Schuff N, Ezekiel F, Gamst AC, et al. Region and tissue differences of metabolites in normally aged brain using multislice $1 \mathrm{H}$ magnetic resonance spectroscopic imaging. Magn Reson Med 2001;45:899-907.

128. Leary SM, Brex PA, MacManus DG, et al. A (1)H magnetic resonance spectroscopy study of aging in parietal white matter: implications for trials in multiple sclerosis. Magn Reson Imaging 2000; 18:455-459.

129. Kreis R, Slotboom J, Hofmann L, Boesch C. Integrated data acquisition and processing to determine metabolite contents, relaxation times, and macromolecule baseline in single examinations of individual subjects. Magn Reson Med 2005;54:761-768.

130. Laule C, Vavasour IM, Moore GRW, et al. Water content and myelin water fraction in multiple sclerosis: a T2 relaxation study. J Neurol 2004;251:284-293.

131. Flynn SW, Lang DJ, Mackay AL, et al. Abnormalities of myelination in schizophrenia detected in vivo with MRI, and postmortem with analysis of oligodendrocyte proteins. Mol Psychiatry $2003 ; 8: 811-820$.
132. Minty E, MacKay A, Whittall KP. Measurement of myelin water in human and bovine spinal cord [abstract]. Int Soc Magn Reson Med Sci, Honolulu, Hawaii, 2002:940.

133. Laule C, Vavasour IM, Vavasour JD, et al. Cervical cord abnormalities in primary progressive multiple sclerosis: atrophy and myelin water changes. Mult Scler 2003;9(suppl 1):S63.

134. Gomez-Anson B, MacManus DG, Parker GJ, et al. In vivo $1 \mathrm{H}-$ magnetic resonance spectroscopy of the spinal cord in humans. Neuroradiology 2000;42:515-517.

135. Kendi AT, Tan FU, Kendi M, et al. MR spectroscopy of cervical spinal cord in patients with multiple sclerosis. Neuroradiology 2004;46:764-769.

136. Marliani AF, Clementi V, Albini-Riccioli L, et al. Quantitative proton magnetic resonance spectroscopy of the human cervical spinal cord at 3 Tesla. Magn Reson Med 2007;57:160-163.

137. Inglese $\mathbf{M}$, Rovaris $\mathrm{M}$, Bianchi $\mathrm{S}$, et al. Magnetic resonance imaging, magnetisation transfer imaging, and diffusion weighted imaging correlates of optic nerve, brain, and cervical cord damage in Leber's hereditary optic neuropathy. J Neurol Neurosurg Psychiatry 2001;70:444-449.

138. Rovaris M, Bozzali M, Rocca MA, et al. An MR study of tissue damage in the cervical cord of patients with migraine. J Neurol Sci 2001;183:43-46.

139. Inglese M, Salvi F, Iannucci G, et al. Magnetization transfer and diffusion tensor MR imaging of acute disseminated encephalomyelitis. AJNR Am J Neuroradiol 2002;23:267-272.

140. Hickman SJ, Hadjiprocopis A, Coulon O, et al. Cervical spinal cord MTR histogram analysis in multiple sclerosis using a 3D acquisition and a B-spline active surface segmentation technique. Magn Reson Imaging 2004;22:891-895.

141. Renoux J, Facon D, Fillard P, et al. MR diffusion tensor imaging and fiber tracking in inflammatory diseases of the spinal cord. AJNR Am J Neuroradiol 2006;27:1947-1951.

142. Hesseltine SM, Law M, Babb J, et al. Diffusion tensor imaging in multiple sclerosis: assessment of regional differences in the axial plane within normal-appearing cervical spinal cord. AJNR Am J Neuroradiol 2006;27:1189-1193.

143. Agosta F, Rocca MA, Benedetti B, et al. MR imaging assessment of brain and cervical cord damage in patients with neuroborreliosis. AJNR Am J Neuroradiol 2006;27:892-894.

144. Filley C. The behavioural neurology of white matter. Oxford, NY: Oxford University Press, 2001.

145. Keegan BM, Noseworthy JH. Multiple sclerosis. Annu Rev Med 2002;53:285-302.

146. Lin F, Yu C, Jiang T, et al. Diffusion tensor tractography-based group mapping of the pyramidal tract in relapsing-remitting multiple sclerosis patients. AJNR Am J Neuroradiol 2007;28:278 282.

147. Larsson HB, Thomsen C, Frederiksen J, et al. In vivo magnetic resonance diffusion measurement in the brain of patients with multiple sclerosis. Magn Reson Imaging 1992;10:7-12.

148. Christiansen P, Gideon P, Thomsen C, et al. Increased water self-diffusion in chronic plaques and in apparently normal white matter in patients with multiple sclerosis. Acta Neurol Scand 1993;87:195-199.

149. Bammer R, Augustin M, Strasser-Fuchs S, et al. Magnetic resonance diffusion tensor imaging for characterizing diffuse and focal white matter abnormalities in multiple sclerosis. Magn Reson Med 2000;44:583-591.

150. Castriota-Scanderbeg A, Sabatini U, Fasano F, et al. Diffusion of water in large demyelinating lesions: a follow-up study. Neuroradiology 2002;44:764-767.

151. Clark CA, Werring DJ, Miller DH. Diffusion imaging of the spinal cord in vivo: estimation of the principal diffusivities and application to multiple sclerosis. Magn Reson Med 2000;43:133138.

152. Agosta F, Benedetti B, Rocca MA, et al. Quantification of cervical cord pathology in primary progressive MS using diffusion tensor MRI. Neurology 2005;64:631-635.

153. Campi A, Filippi M, Comi G, et al. Magnetisation transfer ratios of contrast-enhancing and nonenhancing lesions in multiple sclerosis. Neuroradiology 1996;38:115-119. 
154. Dousset V, Gayou A, Brochet B, Caille JM. Early structural changes in acute MS lesions assessed by serial magnetization transfer studies. Neurology 1998;51:1150-1155.

155. Silver NC, Lai M, Symms MR, et al. Serial magnetization transfer imaging to characterize the early evolution of new MS lesions. Neurology 1998;51:758-764.

156. Rocca MA, Mastronardo G, Rodegher M, et al. Long-term changes of magnetization transfer-derived measures from patients with relapsing-remitting and secondary progressive multiple sclerosis. AJNR Am J Neuroradiol 1999;20:821-827.

157. Cercignani M, Iannucci G, Rocca MA, et al. Pathologic damage in MS assessed by diffusion-weighted and magnetization transfer MRI. Neurology 2000;54:1139-1144.

158. Laule C, Vavasour IM, Whittall KP, et al. Evolution of focal and diffuse magnetisation transfer abnormalities in multiple sclerosis. J Neurol 2003;250:924-931.

159. Barkhof F, Bruck W, De Groot CJ, et al. Remyelinated lesions in multiple sclerosis: magnetic resonance image appearance. Arch Neurol 2003;60:1073-1081.

160. Hiehle JF Jr., Grossman RI, Ramer KN, et al. Magnetization transfer effects in MR-detected multiple sclerosis lesions: comparison with gadolinium-enhanced spin-echo images and nonenhanced T1-weighted images. AJNR Am J Neuroradiol 1995;16: 69-77.

161. Filippi M, Rocca MA, Martino G, et al. Magnetization transfer changes in the normal appearing white matter precede the appearance of enhancing lesions in patients with multiple sclerosis. Ann Neurol 1998;43:809-814.

162. Goodkin DE, Rooney WD, Sloan R, et al. A serial study of new MS lesions and the white matter from which they arise. Neurology 1998;51:1689-1697.

163. Fazekas F, Ropele S, Enzinger C, et al. Quantitative magnetization transfer imaging of pre-lesional white-matter changes in multiple sclerosis. Mult Scler 2002;8:479-484.

164. Levesque I, Sled JG, Narayanan S, et al. The role of edema and demyelination in chronic T1 black holes: a quantitative magnetization transfer study. J Magn Reson Imaging 2005;21:103-110.

165. Davies GR, Tozer DJ, Cercignani M, et al. Estimation of the macromolecular proton fraction and bound pool T2 in multiple sclerosis. Mult Scler 2004;10:607-613.

166. Wolinsky JS, Narayana PA, Fenstermacher MJ. Proton magnetic resonance spectroscopy in multiple sclerosis. Neurology 1990;40: $1764-1769$.

167. Koopmans RA, Li DK, Zhu G, et al. Magnetic resonance spectroscopy of multiple sclerosis: in-vivo detection of myelin breakdown products. Lancet 1993;341:631-632.

168. Davie CA, Hawkins CP, Barker GJ, et al. Detection of myelin breakdown products by proton magnetic resonance spectroscopy. Lancet 1993;341:630-631.

169. Narayana PA, Doyle TJ, Lai D, Wolinsky JS. Serial proton magnetic resonance spectroscopic imaging, contrast-enhanced magnetic resonance imaging, and quantitative lesion volumetry in multiple sclerosis. Ann Neurol 1998;43:56-71.

170. Helms G, Stawiarz L, Kivisakk P, Link H. Regression analysis of metabolite concentrations estimated from localized proton MR spectra of active and chronic multiple sclerosis lesions. Magn Reson Med 2000;43:102-110.

171. Tartaglia MC, Narayanan S, De Stefano N, et al. Choline is increased in pre-lesional normal appearing white matter in multiple sclerosis. J Neurol 2002;249:1382-1390.

172. Cercignani M, Bozzali M, Iannucci G, et al. Magnetisation transfer ratio and mean diffusivity of normal appearing white and gray matter from patients with multiple sclerosis. J Neurol Neurosurg Psychiatry 2001;70:311-317.

173. Kolind SH, Laule C, Li DKB, et al. Identification of destructive lesions in multiple sclerosis: complimentary insights from diffusion and T2 relaxation. Proceedings from the $23^{\text {rd }}$ Annual Scientific Meeting of the European Society of Magnetic Resonance in Medicine and Biology, Warsaw, Poland, 2006:S51.

174. Henry RG, Oh J, Nelson SJ, Pelletier D. Directional diffusion in relapsing-remitting multiple sclerosis: a possible in vivo signature of Wallerian degeneration. J Magn Reson Imaging 2003;18:420426.
175. Vrenken H, Barkhof F, Uitdehaag BM, et al. MR spectroscopic evidence for glial increase but not for neuro-axonal damage in MS normal-appearing white matter. Magn Reson Med 2005;53: 256-266.

176. Filippi M, Campi A, Dousset V, et al. A magnetization transfer imaging study of normal-appearing white matter in multiple sclerosis. Neurology 1995;45:478-482.

177. Leary SM, Silver NC, Stevenson VL, et al. Magnetisation transfer of normal appearing white matter in primary progressive multiple sclerosis. Mult Scler 1999;5:313-316.

178. Allen IV, Glover G, Anderson R. Abnormalities in the macroscopically normal white matter in cases of mild or spinal multiple sclerosis (MS). Acta Neuropathol Suppl (Berl) 1981;7:176-178.

179. Itoyama Y, Sternberger NH, Webster HD, et al. Immunocytochemical observations on the distribution of myelin-associated glycoprotein and myelin basic protein in multiple sclerosis lesions. Ann Neurol 1980;7:167-177.

180. Tourtellotte W, Parker J. Some spaces and barriers in postmortem multiple sclerosis. Prog Brain Res 1968;29:493-525.

181. Alling C, Vanier MT, Svennerholm L. Lipid alterations in apparently normal white matter in multiple sclerosis. Brain Res 1971; 35:325-336.

182. Fewster ME, Hirono H, Mead JF. Lipid composition of myelin in multiple sclerosis. J Neurol 1976;213:119-131.

183. Suzuki K, Kamoshita S, Eto Y, et al. Myelin in multiple sclerosis. Composition of myelin from normal-appearing white matter. Arch Neurol 1973;28:293-297.

184. Evangelou N, Esiri MM, Smith S, et al. Quantitative pathological evidence for axonal loss in normal appearing white matter in multiple sclerosis. Ann Neurol 2000;47:391-395.

185. Evangelou N, Konz D, Esiri MM, et al. Regional axonal loss in the corpus callosum correlates with cerebral white matter lesion volume and distribution in multiple sclerosis. Brain 2000;123: $1845-1849$.

186. Simon JH, Kinkel RP, Jacobs L, et al. A Wallerian degeneration pattern in patients at risk for MS. Neurology 2000;54:1155-1160.

187. Fernando MS, O'Brien JT, Perry RH, et al. Comparison of the pathology of cerebral white matter with post-mortem magnetic resonance imaging (MRI) in the elderly brain. Neuropathol Appl Neurobiol 2004;30:385-395.

188. Sjobeck M, Englund E. Glial levels determine severity of white matter disease in Alzheimer's disease: a neuropathological study of glial changes. Neuropathol Appl Neurobiol 2003;29:159-169.

189. Bartzokis G, Cummings JL, Sultzer D, et al. White matter structural integrity in healthy aging adults and patients with Alzheimer disease: a magnetic resonance imaging study. Arch Neurol 2003; 60:393-398.

190. Bartzokis G, Sultzer D, Lu PH, et al. Heterogeneous age-related breakdown of white matter structural integrity: implications for cortical "disconnection" in aging and Alzheimer's disease. Neurobiol Aging 2004;25:843-851.

191. Bartzokis G, Lu PH, Mintz J. Quantifying age-related myelin breakdown with MRI: novel therapeutic targets for preventing cognitive decline and Alzheimer's disease. J Alzheimers Dis 2004;6:S53-59.

192. House MJ, St Pierre TG, Foster JK, et al. Quantitative MR imaging R2 relaxometry in elderly participants reporting memory loss. AJNR Am J Neuroradiol 2006;27:430-439.

193. Bozzali M, Falini A, Franceschi M, et al. White matter damage in Alzheimer's disease assessed in vivo using diffusion tensor magnetic resonance imaging. J Neurol Neurosurg Psychiatry 2002; 72:742-746.

194. Fellgiebel A, Muller MJ, Wille P, et al. Color-coded diffusiontensor-imaging of posterior cingulate fiber tracts in mild cognitive impairment. Neurobiol Aging 2005;26:1193-1198.

195. Medina D, DeToledo-Morrell L, Urresta F, et al. White matter changes in mild cognitive impairment and AD: A diffusion tensor imaging study. Neurobiol Aging 2006;27:663-672.

196. Naggara O, Oppenheim C, Rieu D, et al. Diffusion tensor imaging in early Alzheimer's disease. Psychiatry Res 2006;146:243-249.

197. Choi SJ, Lim KO, Monteiro I, Reisberg B. Diffusion tensor imaging of frontal white matter microstructure in early Alzhei- 
mer's disease: a preliminary study. J Geriatr Psychiatry Neurol 2005;18:12-19.

198. Back T, Mockel R, Hirsch JG, et al. Combined MR measurements of magnetization transfer, tissue diffusion and proton spectroscopy. A feasibility study with neurological cases. Neurol Res 2003;25:292-300.

199. van Es AC, van der Flier WM, Admiraal-Behloul F, et al. Magnetization transfer imaging of gray and white matter in mild cognitive impairment and Alzheimer's disease. Neurobiol Aging 2006;27:1757-1762.

200. Hanyu H, Asano T, Sakurai H, et al. Diffusion-weighted and magnetization transfer imaging of the corpus callosum in Alzheimer's disease. J Neurol Sci 1999;167:37-44.

201. Kabani NJ, Sled JG, Chertkow H. Magnetization transfer ratio in mild cognitive impairment and dementia of Alzheimer's type. Neuroimage 2002;15:604-610.

202. Bozzali M, Franceschi M, Falini A, et al. Quantification of tissue damage in $\mathrm{AD}$ using diffusion tensor and magnetization transfer MRI. Neurology 2001;57:1135-1137.

203. van der Flier WM, van den Heuvel DM, Weverling-Rijnsburger $\mathrm{AW}$, et al. Magnetization transfer imaging in normal aging, mild cognitive impairment, and Alzheimer's disease. Ann Neurol 2002;52:62-67.

204. Trapp BD, Peterson J, Ransohoff RM, et al. Axonal transection in the lesions of multiple sclerosis. N Engl J Med 1998;338:278285.

205. Kuhn MJ, Mikulis DJ, Ayoub DM, et al. Wallerian degeneration after cerebral infarction: evaluation with sequential MR imaging. Radiology 1989;172:179-182.

206. Lampert PW, Cressman MR. Fine-structural changes of myelin sheaths after axonal degeneration in the spinal cord of rats. Am J Pathol 1966;49:1139-1155.

207. Johnson AC, Mc NA, Rossiter RJ. Chemistry of wallerian degeneration; a review of recent studies. Arch Neurol Psychiatry 1950; 64:105-121.

208. Englund E. Neuropathology of white matter changes in Alzheimer's disease and vascular dementia. Dement Geriatr Cogn Disord 1998;9:6-12.

209. Yoshiura T, Mihara F, Koga H, et al. Mapping of subcortical white matter abnormality in Alzheimer's disease using diffusionweighted magnetic resonance imaging. Acad Radiol 2006;13: $1460-1464$.

210. Cleveland DW, Rothstein JD. From Charcot to Lou Gehrig: deciphering selective motor neuron death in ALS. Nat Rev Neurosci 2001;2:806-819.

211. Buss A, Brook GA, Kakulas B, et al. Gradual loss of myelin and formation of an astrocytic scar during Wallerian degeneration in the human spinal cord. Brain. 2004;127:34-44.

212. Ramon Y, Cajal S. Degeneration and regeneration of white matter. In: DeFilipe J, Jones E, eds. Cajal's Degeneration and Regeneration of the Nervous System. New York: Oxford University Press, 199:57-198.

213. Filbin MT. Myelin-associated inhibitors of axonal regeneration in the adult mammalian CNS. Nat Rev Neurosci 2003;4:703-713.

214. Kerschensteiner M, Schwab ME, Lichtman JW, Misgeld T. In vivo imaging of axonal degeneration and regeneration in the injured spinal cord. Nat Med 2005;11:572-577.

215. van der Knaap MS, Breiter SN, Naidu S, et al. Defining and categorizing leukoencephalopathies of unknown origin: MR imaging approach. Radiology 1999;213:121-133.

216. Barkovich AJ. Concepts of myelin and myelination in neuroradiology. AJNR Am J Neuroradiol 2000;21:1099-1109.

217. Patay Z. Diffusion-weighted MR imaging in leukodystrophies. Eur Radiol 2005;15:2284-2303.

218. Oguz KK, Anlar B, Senbil N, Cila A. Diffusion-weighted imaging findings in juvenile metachromatic leukodystrophy. Neuropediatrics 2004;35:279-282.

219. Sener RN. Diffusion magnetic resonance imaging patterns in metabolic and toxic brain disorders. Acta Radiol 2004;45:561570.

220. Farina L, Bizzi A, Finocchiaro G, et al. MR imaging and proton MR spectroscopy in adult Krabbe disease. AJNR Am J Neuroradiol 2000;21:1478-1482.
221. Zarifi MK, Tzika AA, Astrakas LG, et al. Magnetic resonance spectroscopy and magnetic resonance imaging findings in Krabbe's disease. J Child Neurol 2001;16:522-526.

222. Brockmann K, Dechent P, Meins M, et al. Cerebral proton magnetic resonance spectroscopy in infantile Alexander disease. J Neurol 2003;250:300-306.

223. Brockmann K, Dechent P, Wilken B, et al. Proton MRS profile of cerebral metabolic abnormalities in Krabbe disease. Neurology 2003;60:819-825.

224. Sener RN. Metachromatic leukodystrophy. Diffusion MR imaging and proton MR spectroscopy. Acta Radiol 2003;44:440-443.

225. Austin SJ, Connelly A, Gadian DG, et al. Localized 1H NMR spectroscopy in Canavan's disease: a report of two cases. Magn Reson Med 1991;19:439-445.

226. Wittsack HJ, Kugel H, Roth B, Heindel W. Quantitative measurements with localized 1H MR spectroscopy in children with Canavan's disease. J Magn Reson Imaging 1996;6:889-893.

227. Groenendaal F, Bianchi MC, Battini R, et al. Proton magnetic resonance spectroscopy (1H-MRS) of the cerebrum in two young infants with Zellweger syndrome. Neuropediatrics 2001;32:2327.

228. Kingsley PB, Shah TC, Woldenberg R. Identification of diffuse and focal brain lesions by clinical magnetic resonance spectroscopy. NMR Biomed 2006;19:435-462.

229. Poser CM, Van Bogaert L. Neuro-pathologic observations in phenylketonuria. Brain 1959;82:1-9.

230. Bechar M, Bornstein B, Elian M, Sandbank U. Phenylketonuria presenting an intermittent progressive course. J Neurol Neurosurg Psychiatry 1965;28:165-170.

231. Malamud N. Neuropathology of phenylketonuria. J Neuropathol Exp Neurol 1966;25:254-268.

232. Bauman ML, Kemper TL. Morphologic and histoanatomic observations of the brain in untreated human phenylketonuria. Acta Neuropathol (Berl) 1982;58:55-63.

233. Shah SN, Peterson NA, McKean CM. Lipid composition of human cerebral white matter and myelin in phenylketonuria. J Neurochem 1972;19:2369-2376.

234. Sirrs SM, Laule C, Maedler B, et al. Normal appearing white matter in subjects with phenylketonuria: water content, myelin water fraction, and metabolite concentrations. Radiology 2007; 242:236-243.

235. Dezortova M, Hajek M, Tintera J, et al. MR in phenylketonuriarelated brain lesions. Acta Radiologica 2001;42:459-466.

236. Dezortova M, Hejcmanova L, Hajek M. Decreasing choline signal-a marker of phenylketonuria? MAGMA 1996;4:181-186.

237. Johannik K, Van Hecke P, Francois B, et al. Localized brain proton NMR spectroscopy in young adult phenylketonuria patients. Magn Reson Med 1994;31:53-57.

238. Kono K, Okano Y, Nakayama K, et al. Diffusion-weighted MR imaging in patients with phenylketonuria: relationship between serum phenylalanine levels and ADC values in cerebral white matter. Radiology 2005;236:630-636.

239. Peng SS, Tseng WY, Chien YH, et al. Diffusion tensor images in children with early-treated, chronic, malignant phenylketonuric: correlation with intelligence assessment. AJNR Am J Neuroradiol 2004;25:1569-1574.

240. Leuzzi V, Tosetti M, Montanaro D, et al. The pathogenesis of the white matter abnormalities in phenylketonuria. A multimodal 3.0 tesla MRI and magnetic resonance spectroscopy ([1]H MRS) study. J Inherit Metab Dis 2007;23:23.

241. Hakak Y, Walker JR, Li C, et al. Genome-wide expression analysis reveals dysregulation of myelination-related genes in chronic schizophrenia. Proc Natl Acad Sci U S A. 2001;98:4746-4751.

242. Uranova N, Orlovskaya D, Vikhreva O, et al. Electron microscopy of oligodendroglia in severe mental illness. Brain Res Bull 2001;55:597-610.

243. Tkachev D, Mimmack ML, Huffaker SJ, et al. Further evidence for altered myelin biosynthesis and glutamatergic dysfunction in schizophrenia. Int J Neuropsychopharmacol 2007:1-7.

244. Bartzokis G, Nuechterlein KH, Lu PH, et al. Dysregulated brain development in adult men with schizophrenia: a magnetic resonance imaging study. Biol Psychiatry 2003;53:412-421. 
245. Lui S, Ouyang L, Deng W, et al. Global gray/white matter ratio and gray matter volume reflect abnormal aging neurodevelopment in treatment naive schizophrenics. $14^{\text {th }}$ Annual Meeting of the International Society of Magnetic Resonance in Medicine. Seattle, 2006:2078.

246. Fukuzako H. Neurochemical investigation of the schizophrenic brain by in vivo phosphorus magnetic resonance spectroscopy. World J Biol Psychiatry 2001;2:70-82.

247. Berger GE, Wood SJ, Pantelis C, et al. Implications of lipid biology for the pathogenesis of schizophrenia. Aust N Z J Psychiatry 2002;36:355-366.

248. Tanaka Y, Obata T, Sassa T, et al. Quantitative magnetic resonance spectroscopy of schizophrenia: relationship between decreased $\mathrm{N}$-acetylaspartate and frontal lobe dysfunction. Psychiatry Clin Neurosci 2006;60:365-372.

249. Sigmundsson T, Maier M, Toone BK, et al. Frontal lobe Nacetylaspartate correlates with psychopathology in schizophrenia: a proton magnetic resonance spectroscopy study. Schizophr Res 2003;64:63-71.

250. Lim KO, Hedehus M, Moseley M, et al. Compromised white matter tract integrity in schizophrenia inferred from diffusion tensor imaging. Arch Gen Psychiatry 1999;56:367-374.

251. Agartz I, Andersson JL, Skare S. Abnormal brain white matter in schizophrenia: a diffusion tensor imaging study. Neuroreport 2001;12:2251-2254.

252. Kubicki M, Park H, Westin CF, et al. DTI and MTR abnormalities in schizophrenia: analysis of white matter integrity. Neuroimage 2005;26:1109-1118.

253. Foong J, Maier M, Clark CA, et al. Neuropathological abnormalities of the corpus callosum in schizophrenia: a diffusion tensor imaging study. J Neurol Neurosurg Psychiatry 2000;68:242-244.

254. Brambilla P, Cerini R, Gasparini A, et al. Investigation of corpus callosum in schizophrenia with diffusion imaging. Schizophr Res 2005;79:201-210.

255. Kitamura H, Matsuzawa H, Shioiri T, et al. Diffusion tensor analysis in chronic schizophrenia. A preliminary study on a highfield (3.0T) system. Eur Arch Psychiatry Clin Neurosci 2005;255: 313-318.

256. Pfefferbaum A, Sullivan EV, Hedehus M, et al. Brain gray and white matter transverse relaxation time in schizophrenia. Psychiatry Res 1999;91:93-100.

257. Foong J, Maier M, Barker GJ, et al. In vivo investigation of white matter pathology in schizophrenia with magnetisation transfer imaging. J Neurol Neurosurg Psychiatry 2000;68:70-74.

258. Bagary MS, Symms MR, Barker GJ, et al. Gray and white matter brain abnormalities in first-episode schizophrenia inferred from magnetization transfer imaging. Arch Gen Psychiatry 2003;60: 779-788.

259. Bruck W, Kuhlmann T, Stadelmann C. Remyelination in multiple sclerosis. J Neurol Sci 2003;206:181-185.

260. Moore GRW. Neuropathology and pathophysiology of the multiple sclerosis lesion. In: Paty D, Ebers GC, eds. Multiple Sclerosis. Philadelphia: F.A. Davis, 1998.

261. Yu O, Steibel J, Mauss Y, et al. Remyelination assessment by MRI texture analysis in a cuprizone mouse model. Magn Reson Imaging 2004;22:1139-1144.

262. Merkler D, Boretius S, Stadelmann C, et al. Multicontrast MRI of remyelination in the central nervous system. NMR Biomed 2005; 18:395-403.

263. Blakemore WF. Remyelination of CNS axons by Schwann cells transplanted from the sciatic nerve. Nature 1977;266:68-69.

264. Dunning MD, Lakatos A, Loizou L, et al. Superparamagnetic iron oxide-labeled Schwann cells and olfactory ensheathing cells can be traced in vivo by magnetic resonance imaging and retain functional properties after transplantation into the CNS. J Neurosci 2004;24:9799-9810.

265. Bruck W, Bitsch A, Kolenda H, et al. Inflammatory central nervous system demyelination: correlation of magnetic resonance imaging findings with lesion pathology. Ann Neurol 1997;42: 783-793.

266. Degaonkar MN, Khubchandhani M, Dhawan JK, et al. Sequential proton MRS study of brain metabolite changes monitored during a complete pathological cycle of demyelination and remyelination in a lysophosphatidyl choline (LPC)-induced experimental demyelinating lesion model. NMR Biomed 2002;15:293-300.

267. Vavasour IM, MacKay AL, Whittall KP, et al. A serial magnetic resonance study of multiple sclerosis: T2 relaxation, T1 relaxation and magnetization transfer. Proceedings from the 51st Annual Meeting of the American Academy of Neurology, Toronto, Canada, 1999:A360

268. Chen JT, Collins DL, Freedman MS, et al. Local magnetization transfer ratio signal inhomogeneity is related to subsequent change in MTR in lesions and normal-appearing white-matter of multiple sclerosis patients. Neuroimage 2005;25:1272-1278.

269. Stankiewicz J, Panter SS, Neema M, Arora A, Batt CE, Bakshi R. Iron in chronic brain disorders: Imaging and neurotherapeutic implications. Neurotherapeutics 2007;4:371-386.

270. Henkelman RM, Stanisz GJ, Graham SJ. Magnetization transfer in MRI: a review. NMR Biomed 2001;14:57-64.

271. Suzuki S, Sakai O, Jara H. Combined volumetric T1, T2 and secular-T2 quantitative MRI of the brain: age-related global changes (preliminary results). Magn Reson Imaging 2006;24: 877-887.

272. Ding XQ, Kucinski T, Wittkugel O, et al. Normal brain maturation characterized with age-related $\mathrm{T} 2$ relaxation times: an attempt to develop a quantitative imaging measure for clinical use. Invest Radiol 2004;39:740-746.

273. Moore GRW. MRI-clinical correlations: more than inflammation alone-what can MRI contribute to improve the understanding of pathological processes in MS. J Neurol Sci 2003;206:175179.

274. Larsson HB, Frederiksen J, Kjaer L, et al. In vivo determination of $\mathrm{T} 1$ and $\mathrm{T} 2$ in the brain of patients with severe but stable multiple sclerosis. Magn Reson Med 1988;7:43-55.

275. van Walderveen MA, van Schijndel RA, Pouwels PJ, et al. Multislice T1 relaxation time measurements in the brain using IREPI: reproducibility, normal values, and histogram analysis in patients with multiple sclerosis. J Magn Reson Imaging 2003;18: 656-664.

276. Whittall KP, MacKay AL, Li DK, et al. Normal-appearing white matter in multiple sclerosis has heterogeneous, diffusely prolonged T(2). Magn Reson Med 2002;47:403-408.

277. Sweet RA, Panchalingam K, Pettegrew JW, et al. Psychosis in Alzheimer disease: postmortem magnetic resonance spectroscopy evidence of excess neuronal and membrane phospholipid pathology. Neurobiol Aging 2002;23:547-553.

278. Kantarci K, Petersen RC, Boeve BF, et al. 1H MR spectroscopy in common dementias. Neurology 2004;63:1393-1398.

279. Catani M, Mecocci P, Tarducci R, et al. Proton magnetic resonance spectroscopy reveals similar white matter biochemical changes in patients with chronic hypertension and early Alzheimer's disease. J Am Geriatr Soc 2002;50:1707-1710.

280. Firbank MJ, Harrison RM, O’Brien JT. A comprehensive review of proton magnetic resonance spectroscopy studies in dementia and Parkinson's disease. Dement Geriatr Cogn Disord 2002;14: 64-76.

281. Melberg A, Hallberg L, Kalimo H, Raininko R. MR characteristics and neuropathology in adult-onset autosomal dominant leukodystrophy with autonomic symptoms. AJNR Am J Neuroradiol 2006;27:904-911.

282. Young RS, Osbakken MD, Alger PM, et al. Magnetic resonance imaging in leukodystrophies of childhood. Pediatr Neurol 1985; $1: 15-19$.

283. Ono J, Kodaka R, Imai K, et al. Evaluation of myelination by means of the T2 value on magnetic resonance imaging. Brain Dev 1993; 15:433-438.

284. Spaniel F, Herynek V, Hajek T, et al. Magnetic resonance relaxometry in monozygotic twins discordant and concordant for schizophrenia. Eur Psychiatry 2005;20:41-44.

285. Andreasen NC, Ehrhardt JC, Swayze VW 2nd, et al. T1 and T2 relaxation times in schizophrenia as measured with magnetic resonance imaging. Schizophr Res 1991;5:223-232. 